NBER WORKING PAPER SERIES

\title{
SHOULD UNEMPLOYMENT INSURANCE VARY WITH THE UNEMPLOYMENT RATE? THEORY AND EVIDENCE
}

\author{
Kory Kroft \\ Matthew J. Notowidigdo \\ Working Paper 17173 \\ http://www.nber.org/papers/w17173 \\ NATIONAL BUREAU OF ECONOMIC RESEARCH \\ 1050 Massachusetts Avenue \\ Cambridge, MA 02138 \\ June 2011
}

We thank Joe Altonji, Judy Chevalier, Jonathan Guryan, Erzo Luttmer, Andrew Metrick, Giuseppe Moscarini, Fiona Scott Morton, and seminar participants at Chicago Booth, Federal Reserve Bank of Philadelphia, Harvard, LSE, MIT, NBER, University of Texas at Austin, University of Toronto, Wisconsin, and Yale for providing excellent comments. We thank Jesse Burkhardt and Christian Goldammer for providing outstanding research assistance. Notowidigdo gratefully acknowledges the National Institute of Aging (NIA grant number T32-AG000186) for financial support. The views expressed herein are those of the authors and do not necessarily reflect the views of the National Bureau of Economic Research.

NBER working papers are circulated for discussion and comment purposes. They have not been peerreviewed or been subject to the review by the NBER Board of Directors that accompanies official NBER publications.

(C) 2011 by Kory Kroft and Matthew J. Notowidigdo. All rights reserved. Short sections of text, not to exceed two paragraphs, may be quoted without explicit permission provided that full credit, including (C) notice, is given to the source. 
Should Unemployment Insurance Vary With the Unemployment Rate? Theory and Evidence Kory Kroft and Matthew J. Notowidigdo

NBER Working Paper No. 17173

June 2011

JEL No. H5,J64,J65

\title{
ABSTRACT
}

We study how the level of unemployment insurance (UI) benefits that trades off the consumption smoothing benefit with the moral hazard cost of distorting job search behavior varies over the business cycle. Empirically, we find that the moral hazard cost is procyclical, greater when the unemployment rate is relatively low. By contrast, our evidence suggests that the consumption smoothing benefit of UI is acyclical. Using these estimates to calibrate our model, we find that a one standard deviation increase in the unemployment rate leads to a roughly 14 to 27 percentage point increase in the welfare-maximizing wage replacement rate.

\author{
Kory Kroft \\ Yale University \\ kory.kroft@yale.edu \\ Matthew J. Notowidigdo \\ University of Chicago \\ Booth School of Business \\ 5807 South Woodlawn Avenue \\ Chicago, IL 60637 \\ and NBER \\ noto@chicagobooth.edu
}

An online appendix is available at:

http://www.nber.org/data-appendix/w17173 


\section{Introduction}

It is commonly accepted that raising unemployment insurance (UI) benefits lengthens unemployment spells (Hamermesh 1977, Moffitt 1985, Meyer 1990, Chetty 2008). Higher UI benefits also help smooth consumption, with estimates suggesting modest consumption smoothing benefits (Gruber 1997, Browning and Crossley 2001). This evidence comes from empirical studies that do not distinguish between changes in benefits when labor market conditions are good and changes in benefits when labor market conditions are poor. If the consumption smoothing benefit and moral hazard cost of UI depend on labor market conditions, this may imply that unemployment benefits should respond to shifts in labor demand. However, many of the studies that conduct a welfare analysis of UI do not consider whether and to what extent UI benefits should vary with labor market conditions (Baily 1978, Gruber 1997, Hopenhayn and Nicolini 1997, Chetty 2006, 2008, Shimer and Werning 2007, Kroft 2008, Lentz 2009). As Alan Krueger and Bruce Meyer (2002, p64-65) remark:

$[F]$ or some programs, such as UI, it is quite likely that the adverse incentive effects vary over the business cycle. For example, there is probably less of an efficiency loss from reduced search effort by the unemployed during a recession than during a boom. As a consequence, it may be optimal to expand the generosity of UI during economic downturns ... Unfortunately, this is an area in which little empirical research is currently available to guide policymakers.

Similarly, the Congressional Budget Office writes that the availability of long-term unemployment benefits "could dampen people's efforts to look for work, [but that concern] is less of a factor when employment opportunities are expected to be limited for some time."

This paper investigates how the optimal UI benefit level - which we define throughout the paper as the UI benefit level that trades off the consumption smoothing benefit and the moral hazard cost - varies over the business cycle. We consider a standard job model that has recently been used to evaluate optimal UI (Shimer and Werning 2007, Chetty 2008). In this model, we derive a formula for the marginal welfare gain of UI that illustrates the standard trade-off between the consumption smoothing benefit of UI and the moral hazard

\footnotetext{
${ }^{1}$ The CBO quote is available from the following URL: http://www.washingtonpost.com/wpdyn/content/article/2010/03/08/AR2010030804927_pf.html.
} 
cost of UI. Following prior work, we show that this formula is expressible purely in terms of estimable elasticities. We depart from the prior literature by explicitly allowing these elasticities to depend on the unemployment rate. Identifying the relationship between these elasticities and the unemployment rate is therefore sufficient to characterize optimal UI over the business cycle. This is the objective of our analysis.

Since we state our formula in terms of reduced-form elasticities, our analysis is in the spirit of the "sufficient statistics" approach (Chetty 2009). The primary advantages of this approach are that it is simple to implement and it does not place restrictions on the model primitives. For example, our welfare analysis captures the liquidity benefit of UI (and how this benefit varies over the cycle) without having to model liquidity constraints explicitly. Additionally, our welfare analysis is valid for a wide range of underlying mechanisms which cause the duration elasticity and the consumption smoothing benefit to vary with the unemployment rate. ${ }^{2}$ Most importantly, our welfare analysis does not require separately identifying how reservation wages and search effort respond to a change in benefits and how these behavioral responses vary over the cycle. We demonstrate why this is important by showing that a fixed effort, reservation wage model and a fixed wage, search effort model can give rise to very different predictions about optimal UI over the cycle.

To see part of the intuition for this result, consider the cyclicality of the duration elasticity. We show that there are two opposing forces in the standard search model that shape how this varies over the cycle. On the one hand, in a downturn, the job offer arrival rate or labor demand is less responsive to an increase in labor supply or search effort. This causes the duration elasticity to be smaller in a recession and is related to the speculation of Krueger and Meyer (2002) above. On the other hand, when labor demand is low, a worker values an increase in the benefit level more, since she expects to collect UI for some time. This acts to increase the duration elasticity in a recession. Which effect dominates depends on the assumptions placed on the structural parameters, as we discuss more fully below. We also exploit the structure of our job search model to show that the cyclicality of the consumption

\footnotetext{
${ }^{2}$ Chetty (2009) describes the advantages and disadvantages of the sufficient statistics approach in more detail.
} 
smoothing benefit of UI is ambiguous. ${ }^{3}$

The theoretical ambiguity highlighted by the job search model indicates that how the moral hazard cost and the consumption smoothing benefit of UI vary with labor market conditions is ultimately an empirical question. This motivates our two-part empirical strategy, which directly estimates each of these two terms. The first part of our empirical contribution examines how the elasticity of unemployment duration with respect to the UI benefit level varies with labor market conditions. We estimate a hazard model where the effect of the UI benefit level on unemployment durations depends on the state unemployment rate. We find that the elasticity of unemployment durations with respect to the level of unemployment benefits is 0.563 at the average state unemployment rate, very similar to the estimate reported in Chetty (2008). Our new empirical result is that the duration elasticity varies with local labor market conditions; specifically, we find that the duration elasticity is statistically significantly lower when the state unemployment rate is relatively high. Furthermore, the magnitude of this interaction effect is economically large: in our preferred specification, a one standard deviation increase in the unemployment rate (an increase of 1.3 percentage points from a base of $6.2 \%$ ) reduces the magnitude of the duration elasticity from 0.563 to 0.304 (a decline in magnitude of $46 \%$ ).

The second part of our empirical contribution estimates how the consumption smoothing benefit of UI varies with the unemployment rate. We estimate a model where the effect of UI on the consumption change upon unemployment depends on the state unemployment rate. We find that a ten percentage point increase in the UI replacement rate reduces the consumption drop upon unemployment by $2.6 \%$ on average, very similar to the estimate reported in Gruber (1997). In contrast to our duration elasticity results, we do not find evidence that the consumption smoothing benefit of UI varies with the unemployment rate. Our estimate of the consumption smoothing interaction effect is both economically and statistically insignificant, and - though our statistical power is somewhat limited - we can rule out large effects. As a complementary test, we also do not find evidence that our duration elasticity results

\footnotetext{
${ }^{3}$ To our knowledge, there are few papers that use a standard job search model to derive conditions under which the behavioral responses to UI vary with the job offer arrival rate. We discuss the connection between our theoretical results and the related literature at the end of this section.
} 
are primarily due to liquidity effects varying with local labor market conditions. Putting these two pieces together, they imply that the moral hazard cost of UI is procyclical while the consumption smoothing benefit of UI is acyclical. These findings form the basis of our conclusion that the optimal benefit level is decreasing in the unemployment rate.

The identification of both models comes from exploiting variation in UI benefits within states over time interacted with within- and between-state variation in the unemployment rate. We pursue this time-series, cross-sectional research design using state unemployment rates rather than a purely time-series design using the national unemployment rate in order to have sufficient variation in UI benefit levels across a wide range of labor market conditions. ${ }^{4}$

An immediate concern with our empirical strategy is that when the state unemployment rate is high, benefits may (endogenously) increase. When benefits respond to observed and unobserved labor market conditions, we show that we will consistently estimate our interaction term as long as the correlation between UI benefits and labor market conditions does not vary with the unemployment rate. When this condition is violated, estimates of the interaction term of interest will suffer from endogeneity bias. We pursue three strategies to address this concern.

First, we always measure the local unemployment rate relative to the national unemployment rate, and we control for this relative local unemployment rate directly in all specifications. The use of relative unemployment rates alleviates the concern that UI benefit levels respond to national business cycles. Additionally, if states raise UI benefits in national recessions, but do not systematically adjust benefits in good times, then this strategy is preferable to using absolute unemployment rates with year fixed effects, as we discuss below. By controlling for the local unemployment rate in all specifications, we address the concern that benefits may respond endogenously to local labor market conditions.

Second, we directly investigate the association between the state unemployment rate and the maximum UI benefit level, and we find weak but suggestive evidence that they are

\footnotetext{
${ }^{4}$ Another advantage of our empirical strategy is that in both parts of the empirical analysis, we use the same sample restrictions and empirical specifications from Chetty (2008) and Gruber (1997) in our baseline specifications. Although the samples and specifications vary across these two papers, we minimize issues of data and specification mining, as our baseline sample restrictions and empirical specifications are essentially "pre-specified" by the previous literature.
} 
positively correlated. Moreover, our evidence weakly suggests that the positive association is stronger when the unemployment rate is relatively high. This implies that benefits may respond more strongly to local labor market conditions during bad times. We illustrate with a simple model that this type of differential correlation between the unemployment rate and UI benefits works against our findings. In particular, any omitted variables bias due this type of policy endogeneity will make the duration elasticity artificially larger during times of high unemployment; however, we find the opposite result: the duration elasticity is smaller when the local unemployment rate is relatively high.

Third, we investigate several alternative identifying assumptions to gauge the magnitude of omitted variables bias, and we find, if anything, that our results become stronger. First, we include a flexible polynomial in the state unemployment rate, which addresses the concern that benefits may vary non-linearly with the unemployment rate. Second, we include as additional controls the interaction of the state unemployment rate with state fixed effects and year fixed effects. This allows for a more flexible correlation between observable local labor demand shocks and UI benefits. In particular, it captures the possibility that in certain states and/or years, UI benefits may be unusually responsive to changes in labor market conditions. Third, we investigate alternative specifications which allow for unobserved trends across states within a region and within states over time. Lastly, we find stronger (though less precise) results when we define local labor markets as metropolitan areas (MSAs) rather than states and exploit purely across-MSA, within-state variation in unemployment rates, holding state UI benefit levels constant. We therefore interpret our baseline estimates as a conservative estimate of the magnitude of the relationship between the duration elasticity and the local unemployment rate. We also investigate a wide variety of alternative explanations for this finding, and we find no consistent evidence that the interaction effect we estimate is primarily determined by composition bias, endogenous takeup, or bias from using both between-state and within-state variation in state unemployment rates. Therefore, our interpretation of the duration elasticity results is that they are most consistent with a negative relationship between the moral hazard of cost of UI and the local unemployment rate. 
Combining our reduced form empirical estimates to calibrate the welfare-maximizing UI benefit level implied by our model, we find that a one standard deviation increase in the local unemployment rate leads to a roughly 14 to 27 percentage point increase in the wage replacement rate, depending on the coefficient of relative risk aversion used in the calibration. ${ }^{5}$ To give a sense of the magnitude of a 14 percentage point change in the optimal replacement rate at average levels of unemployment, it is roughly equivalent to the change in the optimal UI benefit level stemming from a one unit change in the coefficient of relative risk aversion (e.g., from $\gamma=3$ to $\gamma=4$ ), holding constant the duration elasticity and the effect of UI on the consumption drop at unemployment.

Our results suggest that if policy makers are designing policy to equate the marginal gain from consumption smoothing to the marginal cost of additional moral hazard, then UI benefits should be countercyclical. This is broadly consistent with the observed UI policy in the U.S., which is based on extending the number of weeks for which an unemployed worker can claim benefits - typically 26 weeks. We show how one can use our elasticity estimates to shed light on the optimality of current UI policy in the U.S., and we also provide an illustration of how one may use our empirical results to shed light on how extending benefits in a recession affects the aggregate unemployment rate.

Our paper builds on and relates to several strands in the literature on optimal UI. First, several papers have explored optimal UI over the business cycle theoretically. Kiley (2003) and Sanchez (2008) consider the dynamic, discrete-time, search effort model in Hopenhayn and Nicolini (1997). They impose particular functional forms on the job finding probability to ensure search effort and a variable affecting the job offer arrival rate are highly complementary. Under these functional forms, UI benefits are more distortionary in good times than bad times, and - as a consequence - optimal UI benefits are unambiguously countercyclical. Andersen and Svarer (2009) consider a static model and impose a similar functional form assumption on the job finding probability. Unlike the previous papers, they incorporate UI financing requirements and show that if the government budget must balance in each state, benefits could be procyclical due to a "budget effect".

\footnotetext{
${ }^{5}$ Given the considerable uncertainty over the value of risk aversion, we report results across a range of CRRA values from $\gamma=2$ to $\gamma=4$.
} 
Our contribution relative to these papers is to consider a more general dynamic search model with stochastic wage offers, as in Shimer and Werning (2007) and Chetty (2008). This framework allows us to shed light on several new dimensions of the optimal UI problem. First, the model permits us to characterize the cyclical behavior of the behavioral responses of both search effort and reservation wages. We demonstrate that a reservation wage model and a search effort model deliver very different predictions about the cyclicality of the duration elasticity. Second, since our model nests other search models used in the literature, we can use the model to zoom in on the distinctions between them. For example, our results highlight that the response of search effort to UI benefits over the cycle is pinned down by three factors - (1) a static effort effect, (2) a dynamic effort effect and (3) a dynamic reservation wage effect - and we show that these effects may go in opposite directions. To our knowledge, previous studies have not highlighted this distinction. ${ }^{6}$

Another strand of the literature has begun to explore optimal UI over the business cycle in a general equilibrium framework. Andersen and Svarer (2010) consider a stylized general equilibrium model, and they demonstrate that allowing for changes in the business cycle situation changes how the distortion to effort created by UI varies over the cycle, since search effort depends on anticipated changes in the labor market. Another general equilibrium approach is Landais, Michaillat, and Saez (2011), who consider a matching model with search effort and focus on characterizing the optimal benefit level over the cycle. The primary innovation in this paper is the introduction of endogenous job rationing coming through the combination of diminishing marginal returns to production and wage rigidity. They derive a version of the Baily-Chetty formula for optimal UI in terms of a "micro" and "macro" elasticity, the latter capturing the direct effect of a change in UI benefits on search and the indirect effect that arises via changes in the aggregate job finding rate. Though our model is a partial equilibrium job search model, it can be reinterpreted as a general equilibrium model following Rogerson, Shimer, and Wright (2005). More specifically, one can interpret our model as the Landais et al. model with the addition of reservation wages and the elimination

\footnotetext{
${ }^{6}$ For example, the typical textbook treatment (e.g., Cahuc and Zylberberg (2004)) simply notes that the simultaneous lowering of the job finding rate and the UI benefit level has an ambiguous effect on optimal job search effort. By contrast, we provide analytical conditions, along with intuition, for the underlying determinants of how the effort elasticity varies with the job offer arrival rate
} 
of job rationing (which would be obtained by assuming constant returns to scale in production, for example).

Finally, while we focus on the optimal level of UI benefits over the business cycle, contemporaneous research by Schmieder, von Wachter and Bender (2011) explore theoretically and empirically the optimal potential duration of UI benefits over the cycle using unique administrative data from Germany. We provide a detailed discussion of the differences between the findings in this paper and our findings in section 3.1.5 below. Overall, we view our work which focuses on the optimal benefit level as highly complementary to work which focuses on optimal potential duration. An important task in future work will be to investigate the problem of jointly choosing the optimal benefit level and potential duration over the business cycle.

The remainder of the paper proceeds as follows. The next section develops the search model and describes our sufficient statistics approach. Section 3 presents our empirical analysis which estimates how the duration elasticity and consumption smoothing benefit of UI vary with the unemployment rate. Section 4 considers the welfare implications of our empirical findings. Section 5 concludes.

\section{Theory}

In this section, we present a standard continuous-time, infinite-time horizon, job search model. The model nests the reservation wage model in Shimer and Werning (2007) and the search effort model in Chetty (2008). For the complete set of analytical results, we refer the reader to the Appendix. We limit the focus here to the setup of the model and a discussion of the intuition underlying the main theoretical results.

\subsection{Assumptions}

We make several assumptions. First, we focus on benefit level, not potential benefit duration. ${ }^{7}$ Second, workers consume hand-to-mouth. Third, there is no value from leisure time

\footnotetext{
${ }^{7}$ Shimer and Werning (2008) find that socially optimal UI policy is infinite duration, constant benefits in a model with free access to savings and lending and CARA preferences.
} 
during an unemployment spell. ${ }^{8}$ Fourth, workers are homogeneous. Finally, we work in a partial equilibrium setting focusing on the worker's problem.

\subsection{Agent's Problem}

We consider a single worker with flow utility $U(c)$, where $U^{\prime}>0, U^{\prime \prime}<0$ and discount rate $\rho \geq 0$ who maximizes

$$
E_{0} \int_{0}^{\infty} e^{-\rho t} U(c(t)) d t
$$

An unemployed worker receives unemployment benefits $b$ and samples wage offers from a known distribution function, $F(w)$, where $f(w)=\frac{d F}{d w}$. Wage offers arrive randomly at rate $\lambda(e, \alpha)$, where $\lambda_{1} \geq 0, \lambda_{11} \leq 0, \lambda_{12} \geq 0$ and $\lambda_{2} \geq 0$. Individuals exert costly search effort, $e$. Following Andersen and Svarer (2009), we assume a linear, separable cost of search, denoted by $\psi(e)$. We characterize business cycles as shifts in labor demand via the parameter $\alpha$, which proxies for productivity. ${ }^{9} \quad$ Workers who accept a wage offer commence employment immediately. When the worker is employed, she earns a wage $w$ and pays taxes $\tau$ which are used to finance unemployment benefit payments. Consumption when employed is her net wage, $w-\tau$. Employment ends exogenously at separation rate $s$. Workers adopt a reservation wage strategy accepting wage offers above the reservation wage, $\bar{w}$, and choose an optimal level of effort $e$. We refer the reader to section A.1 of the Appendix for a full characterization of agent behavior in this model.

\subsection{Elasticity Concepts}

Let $D$ denote expected duration. Define the total elasticity of expected unemployment duration with respect to the UI benefit level as $\varepsilon \equiv \frac{d \log D}{d \log b}$. Section A.2 shows that we can conveniently express the duration elasticity as:

$$
\varepsilon=\varepsilon_{\bar{w}}+\varepsilon_{e}
$$

\footnotetext{
${ }^{8}$ We relax this assumption in Extension 1 in section A.6.1.

${ }^{9}$ In Extension 3 in section A.6.3, we consider business cycles driven by changes in $F(w)$. We show that our main theoretical results in proposition 2 are robust to whether variation in unemployment comes from shifts in the job offer arrival rate or shifts in the wage offer distribution.
} 
The first term in $(2), \varepsilon_{\bar{w}}$, is the duration elasticity in a reservation model with exogenous job offer arrivals (Shimer and Werning 2007). The second term in (2), $\varepsilon_{e}$, is the duration elasticity in a search effort model with a fixed wage (Chetty 2008). Finally, we let $u \equiv$ $\frac{\rho+s}{\rho+s+\lambda(e, \alpha) \bar{F}(\bar{w})}$; when $\rho \approx 0, u$ is the steady-state unemployment rate.

\subsection{Planner's Problem - A Sufficient Statistics Approach}

In this section, we consider the optimal unemployment insurance problem. Our approach is to solve for the level of unemployment benefits that maximize a utilitarian welfare function in a given labor market state. We then focus on the question of how the welfare-maximizing UI benefit level varies over the cycle. Let $V_{u}(b, \tau)$ denote the value function of an unemployed agent. The social planner's problem is stated formally as:

$$
\begin{gathered}
\max _{b, \tau} V_{u}(b, \tau) \\
\text { s.t. } D(b, \tau(b)) b=\frac{\tau}{r+s}
\end{gathered}
$$

The following proposition characterizes the money-metric marginal welfare gain of increasing benefits by $\$ 1$.

Proposition 1 With $r=\rho=0$, the money-metric welfare gain of raising $b$ is given by

$$
\frac{d W}{d b}=\frac{u}{1-u}\left\{\frac{U^{\prime}(b)-E\left[U^{\prime}(w-\tau) \mid w \geq \bar{w}\right]}{E\left[U^{\prime}(w-\tau) \mid w \geq \bar{w}\right]}-\varepsilon\right\}
$$

At the optimum,

$$
\frac{U^{\prime}(b)-E\left[U^{\prime}(w-\tau) \mid w \geq \bar{w}\right]}{E\left[U^{\prime}(w-\tau) \mid w \geq \bar{w}\right]}=\varepsilon
$$

Proof. See section A.3 in the Appendix.

This is the standard "Baily-Chetty condition" of optimal unemployment insurance (Baily 1978, Chetty 2006). ${ }^{10}$ It illustrates the standard trade-off between the insurance role of UI

\footnotetext{
${ }^{10}$ Shimer and Werning (2007) derive a different representation for $d W / d b$ in terms of the responsiveness of the after-tax reservation wage to UI benefits. In section A.4, we formally establish the connection between our expressions.
} 
benefits against the disincentive effect. Moral hazard arises in the second-best world, since agents do not internalize the planner's balanced-budget constraint. Thus, they impose an externality on the planner's budget, captured by the elasticity of expected duration with respect to UI benefits, $\varepsilon$.

To see how optimal UI varies over the cycle, we pursue a "sufficient statistics" approach by estimating directly how each side of (4) varies with the unemployment rate. We describe in detail how we implement this in section 4. The advantage of this approach is that it is less sensitive to the structure of the job search model, which as we now show, if not specified correctly, can lead to potentially misleading conclusions about how optimal UI varies over the cycle.

\subsection{Duration Elasticity Over the Cycle $\left(\frac{d \varepsilon}{d u}\right)$}

In this section, we show that in a standard job search model the cyclicality of the unemployment duration elasticity is theoretically ambiguous. We illustrate this ambiguity by showing that a model with a fixed wage and a search effort margin has a fundamentally different theoretical prediction than a model with a fixed arrival rate and stochastic wage offers. We provide a purely intuition-based explanation of the main effects that cause these two models to have different predictions and refer the interested reader to proposition 2 in section A.5.1 of the Appendix for a more formal presentation and discussion of the results.

\subsubsection{Comparative Statics in Reservation Wage Model $\left(\frac{d \varepsilon_{\bar{w}}}{d u}\right)$}

We begin by calibrating a job search model with a fixed arrival rate $(\lambda(e, \alpha)=\alpha)$ and stochastic wage offers $(w \sim F(w))$ in the spirit of Shimer and Werning (2007). Variation in $\alpha$ generates variation in the unemployment rate, $u$, and this affects the duration elasticity, $\varepsilon_{\bar{w}}$. Figure 1 shows that the duration elasticity is increasing in the unemployment rate, $u$.

Intuitively, the agent's value of unemployment is determined by the unemployment rate when the unemployment rate is high, the agent puts relatively more weight on unemployment consumption utility. This is because she expects to be unemployed next period and so places

relatively more weight on utility in that state. Thus, an increase in UI benefits raises the 
value of unemployment by more when the unemployment rate is high. Since the agent sets the reservation wage so as to equate the value of employment with the value of unemployment, this logic explains why the reservation wage (and, consequently, the duration elasticity) is more responsive to UI benefits when the unemployment rate is high. ${ }^{11}$

\subsubsection{Comparative Statics in Search Effort Model $\left(\frac{d \varepsilon_{e}}{d u}\right)$}

We next calibrate a job search model with a fixed wage $(w)$ and an endogenous arrival rate that depends on search effort $(\lambda(e, \alpha))$ in the spirit of Chetty (2008). As above, variation in $\alpha$ generates variation in the unemployment rate, $u$, and this affects the duration elasticity, $\varepsilon_{e}$. Figure 2 shows that the duration elasticity is decreasing in the unemployment rate, $u$.

In this model, there is a tension between two opposing economic forces in shaping how search effort varies with UI benefits over the cycle. First, there is the direct effect of a recession on the marginal return to search effort. In a recession, individuals cannot affect the job finding probability by much, and therefore benefits do not distort her search effort very much, mitigating the moral hazard cost of benefits in a downturn. In static models (Andersen and Svarer (2009)), this effect fully determines how $\varepsilon_{e}$ varies with $u$, so we label this a "static effort effect".

The opposing force is a "dynamic effort effect". ${ }^{12}$ In a life-cycle model, a permanent increase in benefits raises the value of unemployment in all future periods. The agent's behavioral response is pinned down by the present discounted value of this increase. A negative and permanent labor demand shock lowers search effort, raising the probability of being unemployed in future periods. This makes an increase in UI more valuable and exacerbates the agent's behavioral response in a downturn. Assuming sufficient complementarity between $e$ and $\alpha$ in $\lambda(e, \alpha)$, the static effect will dominate the dynamic effect and $\varepsilon_{e}$ will be procyclical, as can be seen in Figure 2. ${ }^{13}$

\footnotetext{
${ }^{11}$ In terms of our taxonomy of effects, we label this a "discount effect". In proposition 2 (equation 20) in section A.5.1, we show that the sign of $d \varepsilon_{\bar{w}} / d u$ can flip if the agent is sufficiently risk averse, and we label this a "risk aversion effect". In Figure 1, we assume CRRA preferences with a coefficient of relative risk aversion equal to 1.5, and at this value, the "discount effect;' dominates the "risk aversion effect".

${ }^{12}$ Corollaries 1 and 2 in section A.5.1 present expressions for $\partial e / \partial b$ for a fixed wage, dynamic effort model (equation 18) and a fixed wage, static effort model for comparison (equation 19).

${ }^{13}$ In a model with both stochastic wages and endogenous search effort, one also needs to additionally
} 


\subsection{Consumption Smoothing Over the Cycle $\left(\frac{d \bar{g}}{d u}\right)$}

Define $\bar{g}=\frac{U^{\prime}(b)}{E\left[U^{\prime}(w-\tau) \mid w \geq \bar{w}\right]}$ as the money-metric amount such that the government is indifferent between giving $\$ 1$ to someone who is unemployed and $\bar{g}$ to someone who is employed. This parameter captures the degree of consumption smoothing. In proposition 3 of the Appendix, we show that the cyclicality of $\bar{g}$ depends on the relative strengths of (1) a budget effect operating through the balanced-budget condition, (2) a reservation wage effect which comes from the fact that the reservation wage varies over the business cycle, and (3) a liquidity effect. $^{14}$

Combining the duration elasticity and the consumption smoothing terms allow us to solve for the optimal UI benefit level. Figures 1 and 2 plot the optimal UI benefit level as a function of the unemployment rate for the two models above. As expected, whether the optimal benefit level increases or decreases with the unemployment rate depends on the precise specification and specific parameters of the model. Our calibration results suggest that, in contrast with some claims in the literature, the reservation wage model and the fixed-wage, endogenous search effort may have very different implications when considering how UI benefits vary over the cycle. For example, Lentz and Traenes (2005) write that "We do not believe that it is crucial whether the problem is formulated as a choice of reservation wage given a fixed search intensity or (as here) as a choice of search intensity given a fixed wage." While there are many settings where this is true, our calibration results in this section suggest that when studying the interaction between the UI benefit level that trades off consumption smoothing and moral hazard and the unemployment rate, this modeling choice is not innocuous. This theoretical ambiguity motivates the sufficient statistics approach pursued in this paper, which estimates how the duration elasticity and the consumption smoothing benefit vary with the unemployment rate.

account for the effect of benefits on reservation wages as shown in proposition 2 (equation 21) in section A.5.1. We label this a "dynamic reservation wage effect".

${ }^{14}$ In Extension 2 of section A.6.2, we show that if the planner can run deficits in bad times and surpluses in good times and balance the budget across states, the budget effect disappears. 


\section{Empirical Analysis}

The theoretical model above predicts that the unemployment duration elasticity $(\varepsilon)$ and the insurance effect $(\bar{g})$ vary with labor market conditions $(\alpha)$, but the sign and magnitude of these comparative statics are theoretically ambiguous. To take the model to the data, we make three important assumptions.

First, we assume that the predetermined unemployment rate $(u)$ at the start of an unemployment spell is a valid proxy for $\alpha$. Using the predetermined unemployment rate as opposed to the actual unemployment rate at a given time during an unemployment spell - alleviates the concern that the unemployment rate is endogenous to the UI benefit level. Second, we assume that the unemployment rate is constant within an unemployment spell. This assumption is motivated by the fact that virtually all of the variation in unemployment rates is across-spell variation, with negligible within-spell variation. ${ }^{15}$ Lastly, we rely on variation in unemployment rates between and within states, which implicitly assumes that the relevant local labor market conditions are proxied by the state-level unemployment rate. ${ }^{16}$ We pursue this time-series, cross-sectional research design in order to have sufficient variation in UI benefit levels across a wide range of labor market conditions.

\subsection{Part 1: Duration Elasticity}

The first part of the empirical analysis estimates how the duration elasticity varies with the unemployment rate. We present two pieces of evidence: (1) graphical evidence and nonparametric tests of survival curves and (2) semi-parametric estimates of proportional hazard models (Cox models). The empirical strategy closely follows Chetty (2008).

We use unemployment spell data from the Survey of Income and Program Participation (SIPP) spanning 1985-2000. We impose the same sample restrictions as in Chetty (2008): we focus on prime-age males who (1) report searching for a job, (2) are not on temporary

\footnotetext{
${ }^{15} \mathrm{~A}$ variance decomposition of monthly local unemployment rates reveals that $98 \%$ of the variance is between-spell and $2 \%$ is within-spell.

${ }^{16}$ In Table 5, we report results using the unemployment rate in the metropolitan area (MSA) instead, and we find similar results.
} 
layoff, (3) have at least three months of work history, and (4) took up UI benefits. ${ }^{17}$ We also follow Chetty (2008) and censor unemployment spells at 50 weeks. Because of the difficulty in constructing a precise measure of each individual's actual benefit level, we follow Chetty (2008) and use the average benefit level for each state-year pair and the (statutory) maximum weekly benefit amount in the state-year in our baseline specifications. The maximum weekly benefit amount is the primary source of policy variation in benefit levels across states. We also report results using alternative proxies: the average UI replacement rate and a simulated UI benefit variable constructed for each state-year pair by using a UI benefit calculator to calculate the average benefit level for a fixed national sample (Currie and Gruber 1996). All proxies (and all nominal dollar values in the data) are adjusted to real dollars using the 2000 CPI-U series. The precise definition and sources of all variables are described in section A.8 of the Appendix.

\subsubsection{Graphical evidence and nonparametric tests}

We begin by providing graphical evidence on the effect of unemployment benefits on durations. We split the sample into two sub-samples according to whether individuals began their unemployment spell in states with above-median unemployment rates or in states with below-median unemployment rates, where each year we define the median unemployment rate across states that year. We then assign monthly state unemployment rates to unemployment spells based on the unemployment rate in the state that the individual resided in when his

spell began. Lastly, we categorize unemployment spells based on whether the prevailing UI benefit level at the start of the spell in a given state and year is above or below the median UI benefit level across the sample.

Figures 3 and 4 show the effect of UI benefits on the probability of unemployment for individuals in above-average and below-average unemployment state-years, respectively. In each figure, we plot Kaplan-Meier survival curves for individuals in low-benefit and highbenefit states. The results in Figure 3 show that the curves are fairly similar in both low-benefit and high-benefit states when the unemployment rate in a state-year is above the

\footnotetext{
${ }^{17}$ We thank Raj Chetty for assistance with the SIPP data.
} 
median unemployment rate. The curve in high-benefit states is slightly higher, indicating that UI benefits may marginally increase benefits, but a nonparametric test that the curves are identical does not reject at conventional levels $(p=0.599) .{ }^{18}$ By contrast, in Figure 4 the curves are noticeably different; in particular, durations are significantly longer in high-benefit states, and the difference between the survival curves is strongly statistically significant $(p=$ $0.004) \cdot{ }^{19}$

These figures suggest that the moral hazard cost of UI benefits depends crucially on whether unemployment is high or low. In particular, our findings suggest that the effect of UI benefits on durations is not statistically significant when the unemployment rate is high but is strongly statistically significant when the unemployment rate is low. ${ }^{20}$ These effects are based on simple comparisons across spells. It is possible, however, that the characteristics of individuals vary with unemployment rate in a way that would bias these effects. To investigate this issue and other potential biases, as well as to quantify the magnitude of this interaction effect, the next subsection reports results from the estimation of semi-parametric proportional hazard models that include a rich set of individual-level controls. Overall, we find that the results from the hazard models are broadly consistent with the results based on these figures.

\subsubsection{Semiparametric Hazard Models}

We investigate the robustness of the graphical results by estimating a set of Cox proportional hazard models. All results reported standard errors clustered by state. The baseline

\footnotetext{
${ }^{18}$ Across all the figures, we report p-values of log-rank tests of equality across the two survival curves. This is the appropriate test to use when data are censored (as is the case in our data). Results using Wilcoxon rank sum test, as are reported in Chetty (2008), are generally very similar.

${ }^{19}$ While the survival curves are statistically significantly different in Figure 4 but not in Figure 3, one might ask whether the difference-in-difference (DD) across the two figures is statistically significant. To answer this question, we construct a semiparametric test by estimating a Cox proportional hazard model with separate nonparametric baseline hazard estimates for above-median and below-median unemployment state-years. We include two covariates in this Cox model, an indicator for above-median benefits and a DD term which is 1 for above-median benefits in above-median unemployment state-years and 0 otherwise. The p-value on the estimated DD coefficient is 0.050 .

${ }^{20}$ We have also looked at the subsample of workers with above-median liquid wealth, and we find broadly similar results (see Appendix Figures A2 and A3). These results suggest that liquidity effects are not primarily accounting for the differential duration elasticity between high and low unemployment, which is broadly consistent with our results in Table 9, described below.
} 
estimating equation is the following: ${ }^{21}$

$$
\log h_{i, s, t}=\alpha_{t}+\alpha_{s}+\beta_{1} \log \left(b_{s, t}\right)+\beta_{2}\left(\log \left(b_{s, t}\right) \times u_{s, t_{0}}\right)+\beta_{3} u_{s, t_{0}}+\mathbf{X}_{i, s, t} \Gamma+e_{i, s, t}
$$

where $h_{i, s, t}$ is the hazard rate of exit out of unemployment for individual $i$ in state $s$ at time $t$, $\alpha_{t}$ and $\alpha_{s}$ represent year and state fixed effects, $b_{s, t}$ is the unemployment benefit for individual $i$ at the start of the spell based on the state the individual resided in at the start of the spell, and $\mathbf{X}_{i, s, t}$ is a set of (possibly time-varying) control variables. Our primary proxy for local labor market conditions, $u_{s, t_{0}}$, is the log state unemployment rate at the start of the spell relative to the log national unemployment rate. We assign the monthly state unemployment rate based on the month at the start of the spell and the individual's state of residence. For example, if an individual in New York became unemployed in July 2000 and his spell lasted until October 2000, we use the New York unemployment rate in July 2000. The decision to use log unemployment rates follows Bertrand (2004), and we find similar results with the unemployment rate in levels as shown below. We discuss the decision to use relative rather than absolute unemployment rates in detail in section 3.1.3 below. All variables are demeaned so that $-\beta_{1}$ represents the elasticity of unemployment durations with respect to the UI benefit level at the average state unemployment rate. ${ }^{22}$ The coefficient on the interaction term $\left(-\beta_{2}\right)$ is the incremental change in the duration elasticity for a one log point change in the state unemployment rate, holding the national unemployment rate constant.

The identifying assumption that allows us to interpret $\beta_{2}$ as a test of whether the duration elasticity varies with the unemployment rate is the following: conditional on the UI weekly benefit amount, state unemployment rate, state fixed effects, year fixed effects, and control variables, there are no omitted determinants of the duration of an unemployment spell that vary with the interaction of the UI weekly benefit amount and the state unemployment

\footnotetext{
${ }^{21}$ The notation of the estimating equation is a simplified presentation of the true model. The (latent) hazard rate is not actually observed in the data, and there is a flexible (nonparametric) baseline hazard rate which is also estimated when fitting the Cox proportional hazard model. Also, following Chetty (2008), we fit a separate baseline hazard rate for each quartile of net liquid wealth, although our results are very similar when a single nonparametric baseline hazard rate is estimated instead (see Appendix Table A1).

${ }^{22}$ We will use this approximation throughout for the expected unemployment $\operatorname{duration} \log (D) \approx \log (1 / h)=$ $-\log (h)$, so that the duration elasticity and other marginal effects of interest are given by the negative of the coefficient in the hazard model.
} 
rate. This assumption is considerably more plausible with the inclusion of state and year fixed effects, though there remains the concern that benefits respond endogenously to both observed and unobserved local labor market conditions. In section 3.1.3, we discuss this (and many other) threats to validity in more detail.

Before turning to our regression results, we present descriptive statistics for our SIPP sample in Panel A of Table 1. The table presents summary statistics for the overall sample and the two sub-samples used to create Figures 3 and 4. The two sub-samples are broadly similar, though unemployed individuals are slightly older in states with high unemployment. ${ }^{23}$

The main results are reported in Table 2. Following Chetty (2008), the baseline specification controls for age, marital status, years of education, a full set of state, year, industry and occupation fixed effects, and a 10-knot linear spline in log annual wage income. ${ }^{24}$ Column (1) reports estimates of equation (5). The key coefficient of interest is the interaction term between the UI benefit level and the log state unemployment rate. The results indicate that the elasticity of unemployment durations with respect to the UI benefit level $\left(-\beta_{2}\right)$ is 0.563 (s.e. 0.300) at the average unemployment rate. The (average) duration elasticity estimate is broadly similar to the previous literature (Moffitt (1985), Meyer (1990), Chetty (2008)). The results in column (1) show an estimate of $-\beta_{2}$ of -1.262 (s.e. 0.434 ). The bottom two rows of Table 2 report the duration elasticity when the state unemployment rate is one standard deviation (1.3 percentage points) above and below the mean unemployment rate (6.2\%). At one standard deviation above the mean, the duration elasticity is 0.304 (s.e. 0.300), while at one standard deviation below the mean the duration elasticity is 0.822 (s.e. 0.325). In column (2), the average UI benefit level is replaced by the statutory maximum UI benefit level in the state-year, and the results are very similar. In the robustness tests that follow, we will present results which use both the average and the maximum UI benefit level.

\footnotetext{
${ }^{23}$ In Table 6 below, we control for compositional changes in the sample of unemployed individuals across labor market conditions, and we find extremely similar results. We also investigate more systematically how the composition of unemployed workers varies with the unemployment rate in Appendix Table A3.

${ }^{24}$ The only change to the baseline empirical specification in Chetty (2008) that we make is that we do not include the interaction of $\log$ (Average UI WBA) with unemployment duration (i.e., number of weeks elapsed in current spell). This control is intended to capture duration dependence in the response to UI benefits, but because it is difficult to interpret this coefficient and it is always statistically and economically insignificant, we do not include it in any specifications. All results with this interaction term included are extremely similar.
} 
These results imply that the magnitude of the duration elasticity decreases with the unemployment rate and suggest that the moral hazard cost of unemployment insurance is lower when the unemployment rate is relatively high. This empirical finding is consistent with a parameterization of our model where search effort $(e)$ and labor demand conditions $(\alpha)$ are strongly complementary, as in the simulation reported in Figure 2.

\subsubsection{What If UI Benefits Respond to Labor Market Conditions?}

An immediate concern with our identification strategy is that UI benefits may be correlated with unobserved labor market conditions. We pursue several strategies to address this concern. While the sign of the bias due to the endogeneity of UI benefits is not clear a priori, the collection of evidence in this section suggests that our baseline result is likely a conservative estimate (i.e., lower bound) of how the duration elasticity varies with the unemployment rate.

Table 3 reports OLS estimates from several regressions of the log of the maximum UI benefit level on the log of the state unemployment rate relative to the national unemployment rate. The results in this table provide no economically or statistically significant evidence that benefits respond to local labor market conditions. We view this as evidence that UI benefits are plausibly exogenous conditional on state and year fixed effects. Nevertheless, the point estimates in this table suggest that UI benefits may be more responsive to the unemployment rate in bad times than in good times. This type of policy endogeneity would bias estimates of $\beta_{1}$ and $\beta_{2}$ in equation (5), and motivates our analysis to assess the possible bias from such policy endogeneity through several alternative specifications.

In Table 4, we report results which control flexibly for the local unemployment rate and control for unobserved trends. ${ }^{25}$ Column (1) reports our baseline specification for comparison. Columns (2) through (4) include various polynomial functions of the local unemployment rate and the UI benefit level. These tests address the concern that UI benefits respond non-linearly to the local unemployment rate. Additionally, to the extent that the flexible polynomial in the unemployment rate more thoroughly controls for unobserved local labor

\footnotetext{
${ }^{25}$ All of the results in Table 4 are replicated in Appendix Table A1 using the maximum UI benefit level instead of the average UI benefit level, and the results are very similar.
} 
market conditions, this specification can be used to gauge the extent of the bias due to policy endogeneity. Though the results are somewhat less precise, the results in these columns suggest that, if anything, the magnitude of our interaction term is larger with these more flexible controls. ${ }^{26}$ Columns (5) through (7) include specifications which include some combination of interactions between the state unemployment rate and state fixed effects and interactions between the state unemployment rate and year fixed effects. These specifications capture the possibility that in certain states and/or certain years, UI benefits may be unusually responsive to changes in local labor market conditions. Again, the results suggest that, if anything, the magnitude of our interaction term is larger with these more flexible controls. Lastly, columns (8) through (10) report results from modifications of our baseline specification which focus on alternative assumptions regarding contemporaneous trends across states within a region and within states over time. To the extent that such smoothly-varying unobserved trends are correlated with the interaction of local labor market conditions and UI benefit levels, this would cause our baseline specification to be biased. The results in columns (8) through (10) show that results are very similar when we flexibly control for unobserved trends.

Our second strategy formally explores the possibility of unobserved factors determining both UI benefits and unemployment durations. As our empirical strategy is essentially equivalent to estimating a difference-in-differences regression, we consider the case where the unemployment rate $u_{s, t}$ can only take two values: $u_{H}$ and $u_{L}$, with $u_{H}>u_{L} \cdot{ }^{27}$ In this case, estimating equation (5) is equivalent to estimating the following two equations:

$$
\begin{array}{ll}
\log \left(D_{i, H, t}\right)=\beta_{H} \log \left(b_{s, t}\right)+v_{H}+\alpha_{t}+\alpha_{s}+e_{i, H, t} & \text { if } u_{s, t}=u_{H} \\
\log \left(D_{i, L, t}\right)=\beta_{L} \log \left(b_{s, t}\right)+v_{L}+\alpha_{t}+\alpha_{s}+e_{i, L, t} & \text { if } u_{s, t}=u_{L}
\end{array}
$$

The coefficient $\beta_{2}$ on the interaction term $\log \left(b_{s, t}\right) \times u_{s, t}$ in equation (5) is given by the difference between $\beta_{H}$ and $\beta_{L}$. Each of these two equations is subject to a standard identi-

\footnotetext{
${ }^{26}$ We have also investigated robustness to flexible, non-linear effects of UI benefit level in addition to the local unemployment rate. These results are in Appendix Table A2, where we re-estimate our baseline specification with various non-linear (polynomial) functions of the unemployment rate and the UI benefit level. The results are similar to our baseline specification.

${ }^{27}$ This discussion extends Bertrand (2004).
} 
fication problem: each equation is a reduced form equation from a system of two equations, an equation determining durations and an equation determining UI benefits. Consider the following simplified two-equation system:

$$
\begin{aligned}
D_{q} & =\beta_{q} b+\xi_{q} \\
b & =\lambda_{q} \xi_{q}+\eta_{q}
\end{aligned}
$$

where $q=\{H, L\}$. The first equation describes the duration equation and the second equation describes the UI benefit equation. The variable $\xi_{q}$ represents unobserved labor demand shocks which affect both UI benefits and unemployment durations, and $\eta_{q}$ represents unobserved factors which shift UI benefits and are orthogonal to local labor market conditions. We can now ask what happens if one estimates (6) and (7) ignoring the endogeneity of benefits? It is straightforward to show that the estimated coefficient $\widehat{\beta}_{q}$ is given by the following:

$$
\widehat{\beta}_{q}=\beta_{q}+\lambda_{q}
$$

This illustrates the well-known identification problem that $\widehat{\beta}_{q} \neq \beta_{q}$ when $\lambda_{q} \neq 0$. Under the assumption that $\lambda_{q}=0$, it is easy to see that $\beta_{H}$ and $\beta_{L}$ (and therefore $\beta_{H}-\beta_{L}$ ) can be consistently estimated. This assumption requires that all variation in benefits be driven by shocks that are uncorrelated with unobserved labor demand shocks. By contrast, if $\lambda_{q} \neq 0$, we need stronger assumptions for identification. Under the strong assumption that $\lambda_{H}=\lambda_{L}$, then $\widehat{\beta}_{H}-\widehat{\beta}_{L}=\beta_{H}-\beta_{L}$. Thus, while we cannot identify the main effect when $\lambda_{H}=\lambda_{L} \neq 0$, we will be able to consistently estimate the interaction term of interest.

A key remaining challenge arises when $\lambda_{q}$ depends on $q$. For ease of exposition, consider the case where benefits are exogenous in good times, but are endogenous to local labor demand conditions in bad times (e.g., $\lambda_{L}=0$ and $\lambda_{H}>0$ ). In this case, $\widehat{\beta}_{H}-\widehat{\beta}_{L}=\beta_{H}-\beta_{L}+\lambda_{H}$. This illustrates that this particular type of policy endogeneity works against the findings in our baseline specification. Intuitively, if variation in benefits is plausibly exogenous during good times, then we will consistently estimate the duration elasticity in good times; however, if variation in benefits is correlated with unobserved labor market conditions during bad 
times, then this will cause upward bias in the magnitude of the duration elasticity during bad times (e.g., $\widehat{\beta}_{H}=\beta_{H}+\lambda_{H}>\beta_{H}$ ). Since we find that the magnitude of the duration elasticity is significantly smaller during bad times, we conclude that policy endogeneity likely causes us to understate the magnitude of the interaction term.

As a final test of policy endogeneity, Table 5 reports results which use metropolitan areas (MSAs) rather than states to define local labor markets. ${ }^{28}$ By using the MSA unemployment rate instead of the state unemployment rate, we can exploit within-state, across-MSA variation in local labor market conditions, holding UI benefit levels fixed. Columns (1) through (3) report results using the average UI benefit level, while columns (4) through (6) report analogous results using the maximum UI benefit level. Overall, the results across both panels are fairly similar to the baseline specification. In columns (3) and (6), we report results which include a full set of state-by-year fixed effects, so that the only variation used to estimate the interaction term is within-state-year, across-MSA variation in the unemployment rate, holding the state-year UI benefit level constant. The interaction term remains economically and statistically significant at conventional levels in both panels $(p=0.038$ and $p=0.058)$, and the magnitude of the estimates are somewhat larger than in the baseline specification. These results suggest that policy endogeneity is unlikely to account for our results. We note that the results in this table also alleviate the concern that our estimates are confounding state UI potential duration effects with state UI benefit effects, as state-year fixed effects capture all of the variation in the maximum potential duration of UI benefits.

The last threat to identification we discuss comes from the implicit assumption that UI benefits respond symmetrically to both local and national labor market shocks. ${ }^{29}$ If benefits respond to observable and unobservable national labor market conditions, then including year fixed effects, as we do in our baseline specification, addresses the problem. The concern is that when the national labor market is bad, benefits are more correlated with labor market conditions than when national labor market is good. In this case, year fixed effects will

\footnotetext{
${ }^{28}$ To preserve the sample size, we assign the state unemployment rate to all unemployed individuals who do not have an MSA code, which is roughly $50 \%$ of the sample.

${ }^{29}$ A local unemployment shock may differ from a national unemployment shock since it changes mobility incentives. Current U.S. law mandates that individuals collect UI benefits in the state of their previous employer. Given this restriction, we believe the mobility response to UI benefits is likely to be low.
} 
not capture the fact that the correlation between benefits and unobservable labor market conditions depends on the year. One strategy for dealing with this is interacting year fixed effects with UI benefits and including this as a control. This means that any variation in benefits that is correlated with the (unobservables in the) year fixed effects is not variation we use to identify the interaction term. Alternatively, one may use relative unemployment rates to address the concern. In regression results not reported, we find that UI benefits are larger when national unemployment rate is high. We also find results that suggest when the national unemployment rate is high, state benefits are more responsive to relative state unemployment rates. Motivated by this concern, we use the state unemployment rate relative to the national unemployment rate in all specifications. ${ }^{30}$

Overall, given the results in Tables 2 through 5, we interpret our preferred estimate as a conservative estimate of the magnitude of the relationship between the duration elasticity and the local unemployment rate. We find no evidence that a simple policy endogeneity story is primarily responsible for our findings. The next section explores additional threats to validity and alternative explanations for our findings.

\subsubsection{Alternative Explanations and Robustness Tests}

\section{Composition Bias and Endogenous Take-up}

As the local unemployment rate fluctuates, there may be compositional changes in the pool of unemployed workers receiving UI benefits. For example, if there is heterogeneity in moral hazard across demographic groups, and the distribution of demographics of the unemployed varies with the level of unemployment, then this compositional change could generate an observed change in the average duration elasticity. We first note that the appropriate measure for the welfare calibrations below is how the average duration elasticity varies with the unemployment rate, and that this is true whether or not the change in the average duration elasticity is primarily due to compositional changes or individual-level changes in moral hazard. Nevertheless, we investigate the extent to which compositional

\footnotetext{
${ }^{30}$ We find similar results if we include year fixed effects interacted with UI benefits as a control, and we also find similar results when we include the national unemployment rate interacted with UI benefits as a control.
} 
changes can account for our findings, as understanding this may be important for other economic problems.

In Table 6 we report estimates of an augmented version of our baseline specification where we add interactions between UI benefits and the following demographic variables: age, marital status, education, pre-unemployment wage, occupation fixed effects, industry fixed effects. $^{31}$ If the estimate of the baseline interaction term is primarily due to compositional changes among demographic groups with different duration elasticities, then we would expect to see a reduction in the magnitude of the coefficient as we include additional interactions between UI benefits and demographic controls. The results in Table 6 show that our main result is very robust to including such controls - looking across all the columns, we see that adding interactions between demographics and UI benefits has a negligible effect on our main coefficient of interest. ${ }^{32}$

The final column investigates a related source of compositional bias, which is selection bias due to endogenous take-up. As shown in column (9), we find that the effect of UI benefits on take-up varies with the unemployment rate. We also find that the unemployment rate itself is a strong predictor of take-up. These results raise concerns about possible selection bias, though the results in the rest of the columns in Table 6 suggest negligible effects of selection on observables. ${ }^{33}$ While the duration elasticity could also vary with unobservable characteristics of individuals, the robustness to selection on observables suggests that it is unlikely that our interaction term is primarily due to selection on unobservables, though of course we cannot test this directly.

\section{Alternative Measures of the Interaction Term}

\footnotetext{
${ }^{31}$ These tests are motivated by recent work which finds evidence that the composition of unemployed workers varies over the business cycle (Mueller 2010). In Appendix Table A3 we investigate how the composition of workers is associated with the unemployment rate. We do not find significant evidence that the composition of unemployed workers varies with the unemployment rate. In Appendix Table A4, we show that results are very similar to Table 6 when using maximum UI WBA instead of average UI WBA.

${ }^{32}$ The results in this table also reveal suggestive evidence that the duration elasticity varies with years of education. Though accounting for this interaction has no effect on our interaction term of interest, it nevertheless suggests that moral hazard cost may vary with the observable level of human capital.

${ }^{33}$ In results not reported, we find very similar results if we estimate the following two-step estimator. In the first step, we estimate a probit model of UI receipt on interaction term using the same set of controls used in the baseline proportional hazard model using the expanded sample which includes eligibles who do not receive UI benefits. In the second step, we estimate the baseline hazard specification including as an additional control the inverse Mills ratio evaluated at the fitted values.
} 
In our baseline specification, the interaction term of interest is formed by interacting the log of the average weekly UI benefit or the maximum weekly benefit amount in the state with the log of the state unemployment rate (relative to the log of the national unemployment rate). Table 7 explores several alternative measures of the interaction term by using alternative proxies for UI benefits and alternative proxies for local labor demand conditions. Each row of Table 7 reports results from estimating our baseline specification with an alternative measure of our interaction term. The first row reproduces our baseline estimates for comparison. The second row replaces the state unemployment rate with a dummy variable for whether or not the unemployment rate is greater than the median state unemployment rate in that year. This specification corresponds more closely to the nonparametric results presented above. The third row reports results using the state unemployment rate in levels (rather than logs). In both cases, the results are similar to the baseline specification. The fourth row shows that results are similar using the average replacement rate rather than the average weekly UI benefit amount. The fifth row reports reduced form results using a "simulated instrumental variable" following Currie and Gruber (1996). By construction, the variation in this UI benefit variable is only due to changes in program parameters, holding sample composition constant. $^{34}$ Reassuringly, we find similar results to our baseline specification. ${ }^{35}$ The sixth row uses an alternative proxy for local labor demand instead of the local unemployment rate. One concern with the unemployment rate is that it reflects both labor demand and labor supply shocks. We construct variation in state unemployment rates that is driven by plausibly exogenous shifts in local labor demand using a well-established procedure developed in Bartik (1991). ${ }^{36}$ Appendix Figures A4 and A5 plot survival curves comparing the effect of UI benefits across high and low predicted employment-to-population ratios. Consistent with Figures 3 and 4, this nonparametric evidence indicates that the behavioral effect of UI benefits is largest during periods of high predicted employment. Row 6 of Table 7 reports

\footnotetext{
${ }^{34}$ This variable is constructed by using a fixed 20\% 1993 (national) sample and computing the average weekly UI benefit in this fixed sample for every state-year combination in the data set.

${ }^{35}$ Appendix Table A2 reports similar results when this simulated instrument is used as an instrumental variable for the average UI WBA. This is implemented using a two-step control function approach.

${ }^{36}$ We closely following the implementation of the Bartik (1991) procedure in Autor and Duggan (2003). We predict the employment to population ratio by interacting initial cross-sectional distribution of state-level employment shares with national industry employment trends. See the Data Appendix for more details.
} 
hazard model estimates, where the magnitude of the interaction term is similar to our baseline specifications, but our estimates are imprecise.

\section{Decomposing Variation in the State Unemployment Rate}

In our baseline specification, identification of the interaction term of interest comes from both across-state and within-state variation in unemployment rates. Appendix Figures A6 and A7 report survival curves analogous to Figures 3 and 4 using only within-state variation in unemployment rates. We do this by subtracting the unemployment rate in each state-year by the average unemployment rate in the state over the sample period. These figures show that the same pattern in Figures 3 and 4 emerges when using only within-state variation in the unemployment rate. These figures show that there is a statistically significant difference between the high- and low-benefit survival curves when the unemployment rate is relatively low, but not when it is relatively high. Appendix Figures A8 and A9 show similar results using only cross-state variation in the state unemployment. To construct these figures, we compute the average state unemployment rate over the sample period and divide the states based on whether they are above or below the median.

We quantify these patterns in row 7 of Table 7 , where we report results from a specification where we decompose the variation in the state unemployment rate into across-state variation and within-state variation. This specification allows us to see separately how across-state and within-state variation in the state unemployment rate affects the duration elasticity. We find that both interaction terms are the same sign and roughly similar magnitude as the interaction term in the baseline specification. Most importantly, the magnitude of the interaction term using purely within-state variation is very similar to the baseline results. ${ }^{37}$

Finally, Appendix Table A2 reports results using alternative sets of control variables, including controlling for the maximum potential duration of UI benefits, as well as alternative specifications allowing for nonlinear direct effects and specifications which decompose the source of variation in state unemployment rates. The results are similar across these

\footnotetext{
${ }^{37}$ It may be that a national shock is more persistent than a local shock. If we associate the betweenstate variation in unemployment rates with a measure of permanent shocks and the within-state variation with a measure of temporary shocks, we find that with available statistical precision, we cannot reject the hypothesis that the correlation between the duration elasticity and the unemployment rate is the same across both sources of variation.
} 
alternative samples and specifications.

To summarize, across all the specifications in this section, we find no evidence that our baseline results are primarily due to compositional changes, sample selection, mismeasurement, or other spurious factors. We therefore conclude that the most likely explanation for our findings is that the disincentive effect of UI benefits decreases with the unemployment rate.

\subsubsection{Comparison to Schmieder et al. (2011) and Landais et al. (2011)}

While we focus on how the welfare-maximizing UI benefit level varies over the cycle, recent work by Schmieder et al. (2011) considers how the welfare-maximizing potential duration of UI benefits varies over the business cycle. They consider a fixed wage, search effort model and derive a formula for the marginal welfare gain of extending the maximum length of time an individual is eligible to receive UI benefits. Similar to our work, they pursue a sufficient statistics approach and empirically estimate how several of the inputs to their formula vary over the cycle. Specifically, they implement a regression discontinuity design using administrative data from Germany to identify the elasticity of non-employment and actual benefit duration with respect to the potential benefit duration. This research design allows them to very credibly estimate an elasticity for each year in their sample (1987-2004). They show that their annual estimate of the non-employment duration elasticity does not correlate significantly with the annual unemployment rate over this time period. On the other hand, the actual benefit duration elasticity is significantly positively correlated with the unemployment rate. These empirical findings suggest that the welfare gain of an increase UI benefit generosity (in this case, through UI benefit extensions) is higher during recessions.

There are several differences between the studies to highlight: institutional setting (United States versus Germany), research design (fixed effects panel versus regression discontinuity), definition of the labor market (local versus national), UI benefit variation (benefit level versus potential duration). Additionally, the marginal worker affected by the UI variation in their setting is an experienced worker older than age 40, while the UI variation in our setting affects a majority of the workers eligible for UI. All of these differences make the empirical 
estimates not strictly comparable.

The recent work of Landais et al. (2011) also suggests an economic explanation for the differences in results. While we study changes in UI benefit levels which affect a majority of unemployed workers, Schmieder et al. study changes in UI benefit generosity across age thresholds, holding program parameters constant. Therefore, one may interpret the Schmieder et al. estimates as partial equilibrium (PE) estimates and our estimates as general equilibrium (GE) estimates. The logic is that since they analyze the effect of UI by comparing across two groups experiencing the same labor market conditions, it is possible that some of the GE effects of UI are "differenced out". By contrast, our estimation strategy primarily relies on comparing observably similar individuals receiving the same benefits in different labor markets. Under this interpretation, the combined evidence across the two papers suggests that the PE duration elasticity does not vary over the cycle while the GE duration elasticity is strongly decreasing in the unemployment rate. This is precisely the predictions of the job rationing model in Landais et al. (2011), providing a parsimonious ex-

planation for the empirical findings in the two papers. One problem with this interpretation is that the PE estimates in Schmieder et al. are lower than the estimates in this paper, while the Landais et al. paper predicts a larger PE elasticity than GE elasticity. We speculate that this difference may simply be due to different behavioral responses to UI benefit levels versus UI benefit extensions, although we leave a rigorous investigation of this to future work.

\subsection{Part 2: Consumption Smoothing}

The second part of our empirical analysis replicates and extends previous work on the consumption smoothing benefit of UI (Gruber 1997). Specifically, we estimate how the effect of UI on the consumption drop upon unemployment varies with the state unemployment rate in the previous year. The empirical strategy closely follows Gruber (1997), which uses the after-tax UI replacement rate rather than the UI benefit level and uses the change in total food consumption as a proxy for the change in total consumption.

We use data from the Panel Study of Income Dynamics (PSID) between 1968 and 1987. We impose the same sample restrictions as in Gruber (1997): we focus on all heads of house- 
hold who are employed at interview date $t-1$ and unemployed at date $t$, and we define individuals as unemployed if they are looking for a new job and are not on temporary layoff; furthermore, observations are excluded if any element of food consumption is imputed or there is more than a threefold change in total food consumption. We present descriptive statistics for our PSID sample in Panel B of Table 1.

The baseline specification is the following:

$$
\Delta \log C_{i, t}=\alpha_{t}+\alpha_{s}+\delta_{1} b_{i, s, t}+\delta_{2}\left(b_{i, s, t} \times u_{s, t-1}\right)+\delta_{3} u_{s, t-1}+\mathbf{X}_{i, s, t} \Gamma+e_{i, s, t}
$$

where $\Delta \log C_{i, t}$ is the difference in $\log$ total food consumption for individual $i$ between year $t-1$ and year $t, b_{i, s, t}$ is the after-tax UI replacement rate, $u_{s, t-1}$ is the log state unemployment rate relative to the national unemployment rate in year $t-1, \alpha_{t}$ and $\alpha_{s}$ are year and state fixed effects, and $\mathbf{X}_{i, s, t}$ is the same set of control variables used in Gruber (1997). We demean the unemployment rate measure so that $\delta_{1}$ gives the consumption smoothing benefit at average levels of unemployment. ${ }^{38}$

Table 8 reports results of estimating equation (8). Column (1) reproduces column (4) in Table 1 of Gruber (1997) and column (2) reports our replication effort. Column (2) shows the average consumption smoothing benefit of UI $\left(\delta_{1}\right)$ using our replication sample. We find that a ten percentage point increase in the UI replacement rate reduces the consumption drop upon unemployment by $2.6 \%$ (s.e. $1.2 \%$ ). ${ }^{39}$ Column (3) reports our preferred specification which includes the interaction between the replacement rate and the unemployment rate. The estimate on the coefficient of our interaction term is economically and statistically insignificant $\left(\delta_{2}=0.004\right.$, s.e. 0.213$)$. The remaining columns of Table 8 report a variety of alternative of specifications of equation (8), and none of the results in these columns provide any evidence that the consumption smoothing benefit of UI varies with the state unemploy-

\footnotetext{
${ }^{38} \mathrm{As}$ in the first part of the empirical analysis, in our preferred specification we use the log difference between the state unemployment rate and the national unemployment rate. Also, we use the previous year's unemployment rate because we do not observe individuals at the start of their spell, and we want to ensure that the unemployment rate is predetermined, for reasons discussed above.

${ }^{39}$ The coefficient estimates from our replication sample match the results in Gruber (1997) fairly closely. We have been unable to account for the remaining differences. We are grateful to Jonathan Gruber for sharing his UI benefit calculator, which greatly improved our original replication effort.
} 
ment rate. As with the duration elasticity analysis above, the final two rows report estimates at one standard deviation above and below the mean unemployment rate. Unlike the duration elasticity results (which showed that the duration elasticity was significantly lower when the unemployment rate was relatively high), the final two rows in Table 8 consistently show that the consumption smoothing benefit of UI does not vary with the unemployment rate. ${ }^{40}$

In addition to the results based on consumption data, we modify the duration elasticity specifications from above to study the consumption smoothing effect of UI. Chetty (2008) presents evidence that a component of the observed duration elasticity represents an income effect (or "liquidity effect"). This implies greater welfare gains to UI than would be the case if the duration elasticity represented a pure substitution effect, and suggests that the interaction term which we estimate in our baseline specification in the first part of our empirical analysis could plausibly represent a liquidity effect which varies systematically with local labor market conditions. In principle, the consumption smoothing results rule out this possibility as they incorporate liquidity effects. Nevertheless, we present these additional results as a complementary consumption smoothing test (specifically, whether our interaction term in the duration elasticity specification is plausibly driven by liquidity effects). An important caveat to these duration-based results is that - as in Chetty (2008) - these specifications do not exploit plausibly exogenous variation in liquidity constraints, but rather compare duration elasticities across individuals who differ in net liquid wealth.

Table 9 reports these alternative specifications which investigate whether liquidity effects affect the interaction term. Column (1) reports our baseline specification for comparison. Column (2) reports results for the subsample of workers in the 3rd and 4th quartiles of net liquid wealth, where liquidity effects are likely to be less important. The coefficient on the interaction is slightly larger than in the baseline specification. ${ }^{41}$ Columns (3) and (4) report results which include a full set of liquid wealth quartile dummy variables interacted with a combination of occupation fixed effects, industry fixed effects, unemployment duration, and

\footnotetext{
${ }^{40}$ We have also tested whether the consumption level varies with the unemployment rate, and we have found no statistically or economically significant evidence of such an interaction effect.

${ }^{41}$ The interaction term when using the subsample of unemployed workers without a mortgage (another proxy for individuals that are not liquidity constrained used in Chetty (2008)) is even larger in magnitude than columns (1) and (2), again providing no evidence that liquidity effects are primarily responsible for the interaction term in our baseline specification.
} 
the UI benefit level, and the results are, if anything, slightly stronger. Lastly, column (5) verifies that the interaction term does not vary with liquid wealth. The results consistently support the interpretation that the moral hazard cost of UI decreases with the unemployment rate, and that our results are not primarily due to liquidity effects varying with local labor market conditions. More broadly, the results in this table do not provide any evidence that the consumption smoothing benefit (or insurance value) of UI varies with the unemployment rate, which is consistent with the consumption-based tests above.

Overall, we conclude that the consumption smoothing benefit of UI is approximately constant across labor market states. We next conduct a welfare analysis using our empirical results from the two parts of our empirical analysis.

\section{Calibrating the Welfare Implications}

Our empirical results suggest that moral hazard decreases with the unemployment rate. To see what this finding implies for optimal policy, we now calibrate the UI benefit level that trades off the consumption smoothing benefit and the moral hazard cost, following the spirit of the "sufficient statistic" approach to welfare analysis. To review, this method requires using the reduced form empirical estimates as inputs into the optimal UI formula.

One can think of $\varepsilon=h(\log (u))$, where $h()$ is a non-linear function. In order to exploit our empirical estimates, we assume that $h()$ can be locally approximated by a linear function of $\log (u)$. A first-order approximation of $h(\log (u))$ around $\log (u)=\log (\bar{u})$ yields:

$$
\varepsilon(\log (u))=\frac{d \log (D)}{d \log (b)}=-\beta_{1}-\beta_{2} \times(\log (u)-\log (\bar{u}))
$$

where $-\beta_{1}=\varepsilon(\log (\bar{u}))$ and $-\beta_{2}=d \varepsilon / d \log (u)$. Our empirical results imply that $-\widehat{\beta}_{1}=$ 0.563 and $-\widehat{\beta}_{2}=-1.262 .{ }^{42}$

To analyze the welfare implications, recall that the optimal UI benefit level equates the

\footnotetext{
${ }^{42}$ The optimal UI formula in this section delivers the optimal UI replacement rate, which implies that the relevant duration elasticity is the elasticity of unemployment durations with respect to the UI replacement rate, rather than the UI benefit level. For simplicity, we use the results from the baseline specification using the level of benefits, since the duration elasticity results using replacement rate are similar (see row (4) of Table 7).
} 
consumption smoothing benefit with the moral hazard cost of UI as follows:

$$
\frac{U^{\prime}(b)-E\left[U^{\prime}(w-\tau) \mid w \geq \bar{w}\right]}{E\left[U^{\prime}(w-\tau) \mid w \geq \bar{w}\right]}=\varepsilon
$$

Following Chetty (2006), the consumption smoothing benefit can be approximated as

$$
\left[\gamma \frac{\Delta c}{c}(b)\left(1+\frac{1}{2} \delta \frac{\Delta c}{c}(b)\right)+1\right] F-1
$$

where $\gamma$ is the coefficient of relative risk aversion, $\frac{\Delta c}{c}(b)$ is the consumption drop at unemployment as a function of UI benefits, $\delta$ is the coefficient of relative prudence, $F=\frac{1}{1+\frac{1}{2} \gamma \delta s_{e}^{2}}$ is a correction factor that accounts for the volatility in consumption when employed. ${ }^{43}$ It is defined in terms of $s_{e}$, the coefficient of variation of consumption when employed. For ease of computation, we assume a fixed wage, search effort model, so that $F=1$, and we calibrate the consumption smoothing benefit using the estimate for the consumption drop based on our reduced form empirical results. ${ }^{44}$

Given the considerable uncertainty over the value of risk aversion, we present calibration results for a range of values $\gamma=2,3,4$. We choose $\delta=\gamma+1$ for all calibrations, as would be implied by a CRRA utility function. Table 10 presents results from the numerical implementation of expression (4). At $\bar{u}=6.2 \%$ and $\gamma=3$, the optimal replacement rate is $42.8 \%$. At an unemployment rate of $7.5 \%$ (roughly one standard deviation above the mean unemployment rate), the formula implies an optimal replacement rate of $61.4 \%$. Thus, we see that variation in the unemployment rate can substantially affect replacement rates. The basic lesson to emerge from the table is that plausible variation in the unemployment rate generates wide variation in the optimal level of UI. To give a sense of the quantitative importance of this variation, the magnitude is roughly equivalent to a one unit change in

\footnotetext{
${ }^{43}$ Chetty (2006) shows that this approximation is robust to variation in the financial environment. In particular, it does not matter if agents consume hand-to-mouth or have access to liquidity. This result carries over to our setting; as a result, our welfare analysis will be valid, even with savings and borrowing.

${ }^{44}$ To prevent degenerate corner solutions to the planner problem, we assume that the true duration elasticity, $\varepsilon$, is given by the following formula $\hat{\varepsilon}(b /(b+\kappa))$, where $\hat{\varepsilon}$ is the estimated duration elasticity. This ensures an interior solution for all $\kappa>0$. We use $\kappa=0.005$, which gives virtually identical results for all columns in Table 10 except for when risk aversion is low $(\gamma \leq 3)$ and duration elasticity is high $(\hat{\varepsilon}>1)$, in which case this modification raises optimal replacement rate away from 0 by between 1 and 6 percentage points.
} 
the coefficient of relative risk aversion in the model (e.g., from $\gamma=3$ to $\gamma=4$ ), holding the unemployment rate constant. While the previous literature has emphasized the sensitivity of the optimal UI benefit level to the level of risk aversion, our results suggest that the optimal UI benefit level is equally sensitive to labor market conditions. This sensitivity highlights the value of future work which produces more precise estimates of how the duration elasticity and effect of UI on consumption drop at unemployment vary with the unemployment rate.

In terms of existing UI policy in the U.S., the potential duration of UI benefits has typically been adjusted in response to slackness in the labor market, rather than the level of UI benefits. Historically, benefits have been extended by 13 weeks when a state's insured unemployment rate exceeded some threshold (Card and Levine, 2000). In section A.7.1 of the Appendix, we examine both the expected payout from an increase in the unemployment benefit level that trades off the gain from consumption smoothing and the cost of moral hazard and the expected payout from an extension of benefits in line with what we observe with existing UI policy. Our findings indicate that the actual UI policy appears to be slightly less generous in terms of expected payouts as the optimal policy from adjusting the replacement rate would imply.

In section A.7.2 of the Appendix, we also show how one can use our reduced form empirical results to shed light on how extended benefits in the great recession (from 26 to 99 weeks) affected the aggregate unemployment. Our calculations imply that extended benefits can account for roughly $17 \%$ of the observed increase in the aggregate unemployment rate during the great recession in the U.S.. We emphasize that these stylized calculations are primarily meant to be illustrative and that considerable caution should be exercised in interpreting the

quantitative results. Nevertheless, we believe they highlight the substantive importance of our estimates of how the moral hazard cost and consumption smoothing benefits of UI vary with the unemployment rate.

\section{Conclusions}

In this paper, we have considered a standard job search model and have shown that the relationship between both the moral hazard cost and the consumption smoothing benefit of 
UI and the unemployment rate is theoretically ambiguous. This motivated our two-part empirical strategy which (1) estimated how the elasticity of unemployment duration with respect to the UI benefit level varies with the unemployment rate and (2) estimated how the effect of UI on the consumption drop upon unemployment varies with the unemployment rate.

Our empirical findings indicate that the moral hazard cost of UI is lower when unemployment is high, consistent with the speculation of Krueger and Meyer (2002) who claimed that there is likely less of an efficiency loss from reduced search effort by the unemployed when local labor market conditions are poor. On the other hand, we do not find evidence that the consumption smoothing benefit of UI varies with the unemployment rate. We have also shown how one can use the empirical relationship between the duration elasticity and the unemployment rate to calibrate a simple optimal UI formula.

We view the concept that the moral hazard cost of social policies may vary with local labor market conditions as quite general, extending beyond the application of unemployment insurance considered in this paper. It is plausible that the disincentive effects of other government policies may also be lower in times of high unemployment. For example, if the labor supply response to tax changes is lower during recessions, it may be more efficient to redistribute during recessions. In the case of disability insurance and workers compensation, the adverse incentive effect of such programs may also be influenced by the business cycle. It would be interesting to study whether the labor supply elasticities for these programs vary over the business cycle. More generally, to the extent that the moral hazard cost of social insurance programs varies with labor market conditions, one should draw caution in comparing elasticity estimates across studies to the extent that there are different labor market conditions that underlie these estimates.

We conclude with several limitations to our analysis. First, our analysis assumes a stationary job search environment. If duration dependence in job search is important, this can drastically change the implications of our results. In ongoing research, we are working to estimate the role of duration dependence in unemployment, and how duration dependence varies with labor market conditions. 
Second, our results are based on variation in local labor market conditions. Local recessions and aggregate recessions may have very different underlying mechanisms. While the similarity between our state-level and MSA-level results is reassuring, we believe caution should still be exercised in extrapolating our results to national recessions.

Finally, while we focused on the UI benefit level as the policy parameter, in practice, the potential benefit duration is typically extended during times of high unemployment. In ongoing work, we are studying theoretically the welfare-maximizing time path of UI benefits and how this varies with labor market conditions. We hope that this analysis will shed light on UI benefit extension programs in the U.S. and other developed countries.

\section{References}

[1] Andersen, T. M. and M. Svarer (2009), "State Dependent Unemployment Benefits", Journal of Risk and Insurance, forthcoming.

[2] Andersen, T. M. and M. Svarer (2010), "Business Cycle Dependent Unemployment Insurance," IZA DP No. 5196.

[3] Autor, D. and M. Duggan (2003), "The Rise in the Disability Rolls and the Decline in Unemployment", Quarterly Journal of Economics, 118(1) (February): 157-206.

[4] Baily, M. N. (1978), "Some Aspects of Optimal Unemployment Insurance", Journal of Public Economics, 10 (December): 379-402.

[5] Bartik, T. J. (1991), "Who Benefits From State and Local Economic Development Policies", W.E. Upjohn Institute for Employment Research: Kalamazoo, Mich.

[6] Bertrand, Marianne (2004), "From the Invisible Handshake to the Invisible Hand? How Import Competition Changes the Employment Relationship", Journal of Labor Economics, 22(4): 723-766.

[7] Browning, Martin and Thomas F. Crossley (2001), "Unemployment insurance benefit levels and consumption changes", Journal of Public Economics, 80(1): 1-23.

[8] Burdett, K. and J. I. Ondrich (1985), "How Changes in Labor Demand Affect Unemployed Workers", Journal of Labor Economics, 3(1): 1-10.

[9] Card, D. and P.B. Levine (2000), "Extended benefits and the duration of UI spells: evidence from the New Jersey extended benefit program", Journal of Public Economics, (78): 107-138.

[10] Chetty, R. (2006), "A General Formula for the Optimal Level of Social Insurance", Journal of Public Economics 90 (November): 1879-1901. 
[11] Chetty, R. (2008), "Moral Hazard versus Liquidity and Optimal Unemployment Insurance," Journal of Political Economy, 116(2): 173-234.

[12] Chetty, R. (2009), "Sufficient Statistics for Welfare Analysis: A Bridge Between Structural and reduced form Methods", Annual Review of Economics 1: 451-488.

[13] Currie, J. and J. Gruber (1996), "Saving babies: The efficacy and cost of recent changes in the Medicaid eligibility of pregnant women", The Journal of Political Economy 104(6): 1263-1296.

[14] Feldstein, M. and J. Poterba (1984), "Unemployment Insurance and Reservation Wages", Journal of Public Economics 23 (February-March ): 141-67.

[15] Gruber, J. (1997), "The Consumption Smoothing Benefits of Unemployment Insurance", American Economic Review 87 (March): 192-205.

[16] Hamermesh, D. (1977), "Jobless pay, and the economy (Johns Hopkins Press, Baltimore, MD).

[17] Hopenhayn, H. A. and J. Nicolini (1997), "Optimal unemployment insurance", Journal of Political Economy 105: 412-438.

[18] Kiley, M. T. (2003), "How Should Unemployment Benefits Respond to the Business Cycle?", The B.E. Journal of Economic Analysis and Policy. Topics, Vol 3, Issue 1.

[19] Kroft, K. (2008), "Takeup, Social Multipliers and Optimal Social Insurance", Journal of Public Economics, 92: 722-737.

[20] Krueger, A. and B. Meyer (2002), "Labor Supply Effects of Social Insurance" in A. Auerbach and M. Feldstein, eds. Handbook of Public Economics Vol 4. North-Holland: Amsterdam.

[21] Lentz, R. (2009), "Optimal Unemployment Insurance in an Estimated Job Search Model with Savings", Review of Economic Dynamics. Vol 12(1): 37-57.

[22] Landais, C., P. Michaillat and E. Saez (2011). "Optimal Unemployment Insurance over the Business Cycle," NBER Working Paper No. 16526.

[23] Meyer, B. (1990), "Unemployment Insurance and Unemployment Spells". Econometrica 58 (July): 757-782.

[24] Moffitt, R. (1985), "Unemployment Insurance and the Distribution of Unemployment Spells", Journal of Econometrics, 28, 85-101.

[25] Mortensen, D. (1977), "Unemployment Insurance and Job Search Decisions". Industrial and Labor Relations Review, ILR Review, ILR School, Cornell University, 30(4), (July): 505-517.

[26] Mueller, Andreas (2000), "Separations, Sorting and Cyclical Unemployment." Working Paper. 
[27] Røgerson, R., R. Shimer and R. Wright (2005), "Search-Theoretic Models of the Labor Market: A Survey", Journal of Economic Literature, 43(4), 959-988.

[28] Sanchez, J. (2008), "Optimal State-Contingent Unemployment Insurance", Economics Letters, 98(3): 348-357.

[29] Schmieder, J. F., von Wachter, T. and S. Bender (2011), "The Effects of Extended Unemployment Insurance Over the Business Cycle: Evidence from Regression Discontinuity Estimates over Twenty Years", Working Paper.

[30] Shimer, R. and I.Werning (2007), "Reservation Wages and Unemployment Insurance", Quarterly Journal of Economics 122(3): 1145-1185.

[31] Shimer, R. and I.Werning (2008), "Liquidity and Insurance for the Unemployed", American Economic Review, 98(5): 1922-1942.

[32] Van den Berg, G. J. (1994), "The Effects of Changes of the Job Offer Arrival Rate on the Duration of Unemployment", Journal of Labor Economics, 12(3): 478-498. 
Table 1

Descriptive Statistics

\begin{tabular}{|c|c|c|c|c|c|c|c|}
\hline \multicolumn{8}{|c|}{ Panel A: Duration elasticity sample (SIPP) } \\
\hline & \multicolumn{2}{|c|}{ Full Sample } & \multicolumn{2}{|c|}{$\begin{array}{c}\text { State Unemp. Rate } \\
<\text { Median }\end{array}$} & \multicolumn{2}{|c|}{$\begin{array}{c}\text { State Unemp. Rate } \\
\quad \geq \text { Median }\end{array}$} & \multirow{2}{*}{$\begin{array}{c}\mathrm{p} \text {-value of } \\
\text { difference } \\
\text { in means } \\
\end{array}$} \\
\hline & Mean & Std. Dev. & Mean & Std. Dev. & Mean & Std. Dev. & \\
\hline Unemployment duration (weeks) & 18.510 & 14.351 & 16.950 & 13.605 & 19.373 & 14.678 & 0.000 \\
\hline Average UI Weekly Benefit Amount (\$'s) & 163.33 & 26.80 & 163.08 & 26.07 & 163.46 & 27.21 & 0.660 \\
\hline Maximum UI Weekly Benefit Amount (\$'s) & 226.93 & 45.74 & 219.57 & 45.63 & 231.00 & 45.30 & 0.000 \\
\hline Age & 37.17 & 11.07 & 36.59 & 11.11 & 37.48 & 11.03 & 0.011 \\
\hline Years of Education & 12.17 & 2.88 & 12.12 & 2.87 & 12.20 & 2.88 & 0.372 \\
\hline $\mathbf{1}\{$ Married $\}$ & 0.616 & 0.486 & 0.609 & 0.488 & 0.620 & 0.486 & 0.501 \\
\hline Annual wage income (\$000's) & 20.92 & 13.57 & 20.93 & 13.55 & 20.92 & 13.58 & 0.979 \\
\hline $\mathbf{1}\{$ Net liquid wealth in 1 st quartile\} & 0.259 & 0.438 & 0.260 & 0.439 & 0.258 & 0.438 & 0.914 \\
\hline $2\{$ Net liquid wealth in 2nd quartile\} & 0.238 & 0.426 & 0.232 & 0.422 & 0.240 & 0.427 & 0.544 \\
\hline $\mathbf{3}\{$ Net liquid wealth in 3rd quartile\} & 0.271 & 0.444 & 0.273 & 0.446 & 0.269 & 0.444 & 0.775 \\
\hline $\mathbf{4}\{$ Net liquid wealth in 4 th quartile\} & 0.233 & 0.423 & 0.235 & 0.424 & 0.232 & 0.422 & 0.842 \\
\hline \multirow[t]{4}{*}{ Number of Spells } & \multicolumn{2}{|c|}{4307} & \multicolumn{2}{|c|}{2774} & \multicolumn{2}{|c|}{1533} & \\
\hline & Consum & tion chang & e sample & $\underline{\text { PSID) }}$ & & & \\
\hline & \multicolumn{2}{|c|}{ Full Sample } & \multicolumn{2}{|c|}{$\begin{array}{l}\text { State Unemp. Rate } \\
<\text { Median }\end{array}$} & \multicolumn{2}{|c|}{$\begin{array}{c}\text { State Unemp. Rate } \\
\geq \text { Median }\end{array}$} & \multirow{2}{*}{$\begin{array}{c}\mathrm{p} \text {-value of } \\
\text { difference } \\
\text { in means }\end{array}$} \\
\hline & Mean & Std. Dev. & Mean & Std. Dev. & Mean & Std. Dev. & \\
\hline Change in log consumption upon unemp. & -0.070 & 0.415 & -0.061 & 0.402 & -0.079 & 0.427 & 0.396 \\
\hline After-tax UI Replacement Rate & 0.606 & 0.155 & 0.599 & 0.153 & 0.613 & 0.156 & 0.083 \\
\hline Age & 34.58 & 11.44 & 34.38 & 11.21 & 34.77 & 11.64 & 0.498 \\
\hline $\mathbf{1}\{$ Female $\}$ & 0.233 & 0.423 & 0.250 & 0.433 & 0.217 & 0.413 & 0.129 \\
\hline $\mathbf{1}\{$ Married $\}$ & 0.571 & 0.495 & 0.565 & 0.496 & 0.576 & 0.495 & 0.661 \\
\hline $\mathbf{1}\{$ White $\}$ & 0.496 & 0.500 & 0.495 & 0.500 & 0.496 & 0.500 & 0.964 \\
\hline $\mathbf{1}\{$ Black $\}$ & 0.460 & 0.499 & 0.478 & 0.500 & 0.444 & 0.497 & 0.180 \\
\hline Change in log food needs & 0.002 & 0.255 & 0.002 & 0.254 & 0.003 & 0.256 & 0.910 \\
\hline Number of Children Under 18 & 1.240 & 1.422 & 1.223 & 1.391 & 1.255 & 1.449 & 0.650 \\
\hline Number of Observations & \multicolumn{2}{|c|}{1595} & \multicolumn{2}{|c|}{749} & \multicolumn{2}{|c|}{846} & \\
\hline
\end{tabular}

Notes: In Panel A, data are individual-level unemployment spells from 1985-2000 SIPP. Average UI Weekly Benefit Amount and Maximum UI Weekly Benefit Amount and all other dollar values are reported as 2000 CPI-U-adjusted dollars. In Panel B, data are individual-level observations from 1968-1987 PSID. The after-tax UI replacement rate is constructed using the UI benefit calculator in Gruber (1997). See main text and Data Appendix for more details. 
Table 2

How Does Duration Elasticity Vary With the Unemployment Rate?

\begin{tabular}{|c|c|c|}
\hline & $\begin{array}{l}\text { Average } \\
\text { UI WBA }\end{array}$ & $\begin{array}{l}\text { Maximum } \\
\text { UI WBA }\end{array}$ \\
\hline & (1) & $(2)$ \\
\hline \multirow[t]{3}{*}{$\log (\mathrm{UI}$ WBA $)$} & -0.563 & -0.228 \\
\hline & $(0.300)$ & $(0.253)$ \\
\hline & {$[0.060]$} & [0.368] \\
\hline $\log ($ UI WBA $) \times$ & 1.262 & 1.219 \\
\hline \multirow[t]{2}{*}{ log(State Unemp. Rate / National Unemp. Rate) } & $(0.434)$ & (0.469) \\
\hline & {$[0.004]$} & [0.009] \\
\hline \multirow[t]{3}{*}{ log(State Unemp. Rate / National Unemp. Rate) } & -0.014 & 0.010 \\
\hline & $(0.119)$ & $(0.130)$ \\
\hline & {$[0.908]$} & [0.940] \\
\hline \multirow[t]{3}{*}{ Age } & -0.017 & -0.017 \\
\hline & $(0.002)$ & $(0.002)$ \\
\hline & {$[0.000]$} & [0.000] \\
\hline \multirow[t]{3}{*}{ Marital Dummy } & 0.208 & 0.211 \\
\hline & $(0.040)$ & $(0.040)$ \\
\hline & {$[0.000]$} & [0.000] \\
\hline \multirow[t]{3}{*}{ Years of Education } & 0.004 & 0.004 \\
\hline & $(0.006)$ & $(0.006)$ \\
\hline & {$[0.505]$} & [0.491] \\
\hline Number of Spells & 4307 & 4307 \\
\hline \multirow[t]{3}{*}{ Post-estimation: (A) $+\sigma \times(\mathbf{B})$} & -0.304 & 0.022 \\
\hline & $(0.300)$ & $(0.239)$ \\
\hline & {$[0.310]$} & [0.927] \\
\hline \multirow[t]{3}{*}{ Post-estimation: (A) $-\sigma \times$ (B) } & -0.822 & -0.477 \\
\hline & $(0.325)$ & $(0.299)$ \\
\hline & [0.011] & [0.110] \\
\hline
\end{tabular}

Notes: All columns report semiparametric (Cox proportional) hazard model results from estimating equation (5). Data are individual-level unemployment spells from 1985-2000 SIPP. All specifications include state, year, industry and occupation fixed effects, 10-knot linear spline in log annual wage income and a control for being on the seam between interviews to adjust for the "seam effect." The Average UI WBA is the average weekly benefit amount paid to individuals claiming unemployment insurance in a given state. The Maximum UI WBA is the statutory weekly benefit amount paid to high wage earners in a state. All columns estimate nonparametric baseline hazards stratified by quartile of net liquid wealth. The final two rows report linear combinations of parameter estimates to produce the duration elasticity when the state unemployment rate is one standard deviation above/below the mean. Standard errors, adjusted to allow for an arbitrary variance-covariance matrix for each state over time, are in parentheses and p-values are in brackets. 
Table 3

How Do UI Benefits Vary With the Unemployment Rate?

Dependent variable: Log of Maximum UI Weekly Benefit Amount

Sample Restrictions:

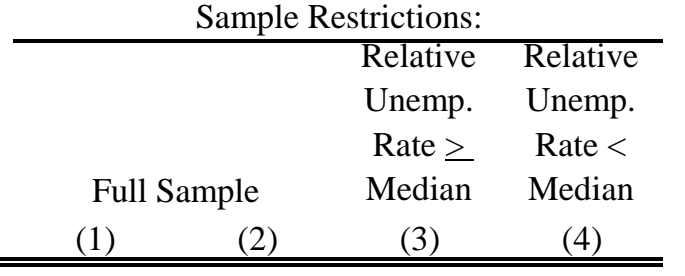

\begin{tabular}{|c|c|c|c|c|}
\hline \multicolumn{5}{|c|}{ Panel A: State FEs + Year FEs } \\
\hline $\log$ (State Unemp. Rate / National Unemp. Rate) & 0.080 & 0.103 & 0.117 & 0.008 \\
\hline \multirow{5}{*}{$(\log (\text { State Unemp. Rate / National Unemp. Rate }))^{2}$} & $(0.050)$ & $(0.062)$ & $(0.137)$ & $(0.088)$ \\
\hline & [0.122] & {$[0.104]$} & [0.399] & [0.924] \\
\hline & & 0.100 & & \\
\hline & & $(0.107)$ & & \\
\hline & & {$[0.355]$} & & \\
\hline $\mathrm{N}$ & 672 & 672 & 336 & 336 \\
\hline \multicolumn{5}{|c|}{ Panel B: State FEs + Year FEs + State-specific linear trends } \\
\hline \multirow{2}{*}{$\log$ (State Unemp. Rate / National Unemp. Rate) } & 0.054 & 0.089 & 0.127 & -0.012 \\
\hline & $(0.038)$ & $(0.046)$ & $(0.093)$ & $(0.060)$ \\
\hline \multirow{4}{*}{$(\log (\text { State Unemp. Rate / National Unemp. Rate }))^{2}$} & [0.167] & [0.062] & [0.183] & [0.842] \\
\hline & & 0.130 & & \\
\hline & & $(0.093)$ & & \\
\hline & & {$[0.171]$} & & \\
\hline $\mathrm{N}$ & 672 & 672 & 336 & 336 \\
\hline
\end{tabular}

Notes: All columns report OLS regressions with the log of the statutory maximum weekly UI benefit in the state as the dependent variable. Data set is state-level panel of the 42 states used in the baseline SIPP sample between 1985 and 2000. Standard errors, adjusted to allow for an arbitrary variance-covariance matrix for each state over time, are in parentheses and p-values are in brackets. 
Table 4

Allowing UI Benefits to Respond Flexibly to the Unemployment Rate and Flexibly Controlling for Unobserved Trends

\begin{tabular}{|c|c|c|c|c|c|c|c|c|c|c|}
\hline & (1) & (2) & (3) & (4) & (5) & (6) & (7) & (8) & (9) & (10) \\
\hline \multirow[t]{3}{*}{$\log ($ Average UI WBA) } & -0.563 & -0.572 & -0.706 & -0.659 & -0.748 & -0.593 & -0.541 & -0.725 & -0.553 & -0.808 \\
\hline & $(0.300)$ & (0.329) & $(0.362)$ & $(0.342)$ & $(0.324)$ & $(0.344)$ & $(0.365)$ & $(0.361)$ & $(0.443)$ & $(0.449)$ \\
\hline & {$[0.060]$} & {$[0.082]$} & {$[0.051]$} & {$[0.054]$} & {$[0.021]$} & {$[0.085]$} & {$[0.138]$} & {$[0.044]$} & {$[0.211]$} & {$[0.072]$} \\
\hline \multirow{3}{*}{$\begin{array}{l}\log (\text { Average UI WBA) } \times \\
\quad \log (\text { State Unemp. Rate / National Unemp. Rate })\end{array}$} & 1.262 & 1.270 & 1.606 & 1.744 & 2.584 & 1.324 & 2.530 & 1.435 & 1.740 & 1.236 \\
\hline & $(0.434)$ & $(0.465)$ & $(0.445)$ & $(0.477)$ & (1.208) & (0.387) & $(0.902)$ & (0.515) & $(0.840)$ & (0.547) \\
\hline & {$[0.004]$} & {$[0.006]$} & {$[0.000]$} & {$[0.000]$} & {$[0.032]$} & {$[0.001]$} & {$[0.005]$} & {$[0.005]$} & {$[0.038]$} & {$[0.024]$} \\
\hline Quadratic in State Unemployment Rate & $\mathrm{N}$ & $\mathrm{Y}$ & $\mathrm{N}$ & $\mathrm{N}$ & $\mathrm{N}$ & $\mathrm{N}$ & $\mathrm{N}$ & $\mathrm{N}$ & $\mathrm{N}$ & $\mathrm{N}$ \\
\hline Cubic in State Unemployment Rate & $\mathrm{N}$ & $\mathrm{N}$ & $\mathrm{Y}$ & $\mathrm{N}$ & $\mathrm{N}$ & $\mathrm{N}$ & $\mathrm{N}$ & $\mathrm{N}$ & $\mathrm{N}$ & $\mathrm{N}$ \\
\hline Quartic in State Unemployment Rate & $\mathrm{N}$ & $\mathrm{N}$ & $\mathrm{N}$ & $\mathrm{Y}$ & $\mathrm{N}$ & $\mathrm{N}$ & $\mathrm{N}$ & $\mathrm{N}$ & $\mathrm{N}$ & $\mathrm{N}$ \\
\hline State FEs x State Unemployment Rate & $\mathrm{N}$ & $\mathrm{N}$ & $\mathrm{N}$ & $\mathrm{N}$ & $\mathrm{Y}$ & $\mathrm{N}$ & $\mathrm{Y}$ & $\mathrm{N}$ & $\mathrm{N}$ & $\mathrm{N}$ \\
\hline Year FEs x State Unemployment Rate & $\mathrm{N}$ & $\mathrm{N}$ & $\mathrm{N}$ & $\mathrm{N}$ & $\mathrm{N}$ & $\mathrm{Y}$ & $\mathrm{Y}$ & $\mathrm{N}$ & $\mathrm{N}$ & $\mathrm{N}$ \\
\hline Region-specific linear time trends & $\mathrm{N}$ & $\mathrm{N}$ & $\mathrm{N}$ & $\mathrm{N}$ & $\mathrm{N}$ & $\mathrm{N}$ & $\mathrm{N}$ & $\mathrm{Y}$ & $\mathrm{N}$ & $\mathrm{N}$ \\
\hline Region $\times$ Year FEs & $\mathrm{N}$ & $\mathrm{N}$ & $\mathrm{N}$ & $\mathrm{N}$ & $\mathrm{N}$ & $\mathrm{N}$ & $\mathrm{N}$ & $\mathrm{N}$ & $\mathrm{Y}$ & $\mathrm{N}$ \\
\hline State-specific linear time trends & $\mathrm{N}$ & $\mathrm{N}$ & $\mathrm{N}$ & $\mathrm{N}$ & $\mathrm{N}$ & $\mathrm{N}$ & $\mathrm{N}$ & $\mathrm{N}$ & $\mathrm{N}$ & $\mathrm{Y}$ \\
\hline \multirow[t]{3}{*}{ Post-estimation: (A) $+\sigma \times \mathbf{( B )}$} & -0.304 & -0.312 & -0.377 & -0.302 & -0.219 & -0.322 & -0.023 & -0.431 & -0.197 & -0.555 \\
\hline & $(0.300)$ & $(0.316)$ & $(0.340)$ & $(0.317)$ & $(0.332)$ & $(0.328)$ & $(0.372)$ & (0.373) & $(0.451)$ & $(0.475)$ \\
\hline & {$[0.310]$} & {$[0.324]$} & {$[0.267]$} & {$[0.341]$} & {$[0.510]$} & {$[0.327]$} & {$[0.951]$} & {$[0.248]$} & {$[0.663]$} & {$[0.242]$} \\
\hline \multirow[t]{3}{*}{ Post-estimation: (A) $-\sigma \times$ (B) } & -0.822 & -0.832 & -1.035 & -1.016 & -1.278 & -0.865 & -1.060 & -1.019 & -0.910 & -1.062 \\
\hline & $(0.325)$ & $(0.367)$ & $(0.404)$ & $(0.390)$ & $(0.471)$ & (0.377) & $(0.443)$ & (0.379) & $(0.498)$ & $(0.450)$ \\
\hline & [0.011] & {$[0.024]$} & [0.010] & [0.009] & [0.007] & [0.022] & [0.017] & [0.007] & [0.068] & [0.018] \\
\hline
\end{tabular}

Notes: All columns report semiparametric (Cox proportional) hazard model results from estimating equation (5). Data are individual-level unemployment spells from 1985-2000 SIPP. Number of spells = 4307. See Table 2 for more details on the baseline specification and Appendix Table A1 for analogous results usin the Maximum UI WBA. The final two rows reports linear combinations of parameter estimates to produce the duration elasticity when the state unemployment rate is one standard deviation above/below the mean. Standard errors, adjusted to allow for an arbitrary variance-covariance matrix for each state over time, are in parentheses and p-values are in brackets. 
Table 5

Exploiting Variation Across Metropolitan Areas Within States

\begin{tabular}{|c|c|c|c|c|c|c|}
\hline & \multicolumn{3}{|c|}{ Average UI WBA } & \multicolumn{3}{|c|}{ Maximum UI WBA } \\
\hline & (1) & $(2)$ & (3) & (4) & (5) & (6) \\
\hline \multirow[t]{3}{*}{$\log (\mathrm{UI}$ WBA $)$} & -0.364 & -0.877 & & -0.127 & -0.396 & \\
\hline & $(0.292)$ & $(0.480)$ & & $(0.240)$ & $(0.214)$ & \\
\hline & {$[0.214]$} & {$[0.068]$} & & [0.596] & [0.064] & \\
\hline \multirow{3}{*}{$\begin{array}{l}\log (\text { UI WBA }) \times \quad \text { (B) } \\
\quad \log (\text { Metropolitan Unemp. Rate / National Unemp. Rate })\end{array}$} & 0.991 & 1.284 & 2.009 & 0.993 & 1.382 & 1.937 \\
\hline & $(0.393)$ & $(0.481)$ & $(0.971)$ & $(0.450)$ & $(0.530)$ & (1.021) \\
\hline & {$[0.012]$} & {$[0.008]$} & {$[0.038]$} & {$[0.027]$} & [0.009] & [0.058] \\
\hline \multirow[t]{3}{*}{ log(Metropolitan Unemp. Rate / National Unemp. Rate) } & -0.064 & 0.010 & 0.078 & -0.050 & -0.003 & 0.072 \\
\hline & $(0.094)$ & $(0.096)$ & $(0.157)$ & $(0.105)$ & $(0.111)$ & $(0.154)$ \\
\hline & {$[0.496]$} & {$[0.921]$} & {$[0.620]$} & {$[0.637]$} & {$[0.976]$} & {$[0.641]$} \\
\hline MSA FEs + Year FEs & $\mathrm{Y}$ & $\mathrm{Y}$ & $\mathrm{Y}$ & $\mathrm{Y}$ & $\mathrm{Y}$ & $\mathrm{Y}$ \\
\hline State-specific linear time trends & $\mathrm{N}$ & $\mathrm{Y}$ & $\mathrm{N}$ & $\mathrm{N}$ & $\mathrm{Y}$ & $\mathrm{N}$ \\
\hline State $\times$ Year FEs & $\mathrm{N}$ & $\mathrm{N}$ & $\mathrm{Y}$ & $\mathrm{N}$ & $\mathrm{N}$ & $\mathrm{Y}$ \\
\hline \multirow[t]{3}{*}{ Post-estimation: (A) $+\sigma \times$ (B) } & -0.082 & -0.511 & & 0.155 & -0.003 & \\
\hline & $(0.296)$ & $(0.509)$ & & $(0.230)$ & $(0.253)$ & \\
\hline & [0.783] & [0.315] & & [0.498] & [0.990] & \\
\hline \multirow[t]{3}{*}{ Post-estimation: (A) $-\sigma \times$ (B) } & -0.646 & -1.243 & & -0.410 & -0.790 & \\
\hline & $(0.329)$ & $(0.490)$ & & $(0.309)$ & $(0.270)$ & \\
\hline & {$[0.050]$} & {$[0.011]$} & & [0.184] & [0.003] & \\
\hline
\end{tabular}

Notes: All columns report semiparametric (Cox proportional) hazard model results from estimating equation (5). Data are individual-level unemployment spells from 1985-2000 SIPP. Number of spells $=4307$. See Table 2 for more details on the baseline specification. To preserve sample size, observations without MSA codes are grouped together within a state and assigned the state unemployment rate. The final two rows reports linear combinations of parameter estimates to produce the duration elasticity when the state unemployment rate is one standard deviation above/below average. Standard errors, adjusted to allow for an arbitrary variance-covariance matrix for each state over time, are in parentheses and p-values are in brackets. 
Table 6

How Much Do Demographics Explain Why Moral Hazard Varies

with the State Unemployment Rate?

\begin{tabular}{|c|c|c|c|c|c|c|c|c|c|}
\hline \multirow[t]{2}{*}{ Dependent variable: } & \multicolumn{8}{|c|}{ Unemployment Duration } & \multirow{2}{*}{$\begin{array}{l}\text { Take-up } \\
\text { Dummy } \\
(9)\end{array}$} \\
\hline & (1) & (2) & (3) & (4) & (5) & (6) & (7) & (8) & \\
\hline \multirow[t]{3}{*}{ log(Average UI WBA) } & -0.563 & -0.551 & -0.563 & -0.541 & -0.559 & -0.488 & -0.482 & -0.450 & 0.105 \\
\hline & $(0.300)$ & $(0.296)$ & $(0.300)$ & $(0.295)$ & $(0.298)$ & $(0.300)$ & $(0.320)$ & $(0.304)$ & $(0.079)$ \\
\hline & {$[0.060]$} & {$[0.063]$} & {$[0.060]$} & {$[0.067]$} & {$[0.061]$} & {$[0.103]$} & [0.132] & {$[0.138]$} & [0.192] \\
\hline \multirow{2}{*}{$\begin{array}{l}\log (\text { Average UI WBA }) \times \\
\log (\text { State Unemp. Rate } /\end{array}$} & 1.262 & 1.249 & 1.262 & 1.255 & 1.271 & 1.271 & 1.212 & 1.243 & -0.313 \\
\hline & $(0.434)$ & $(0.435)$ & $(0.428)$ & $(0.438)$ & $(0.430)$ & $(0.443)$ & $(0.413)$ & $(0.407)$ & $(0.134)$ \\
\hline National Unemp. Rate ) & {$[0.004]$} & [0.004] & {$[0.003]$} & {$[0.004]$} & {$[0.003]$} & {$[0.004]$} & {$[0.003]$} & [0.002] & [0.024] \\
\hline \multirow{3}{*}{$\begin{array}{l}\log \text { (State Unemp. Rate / } \\
\text { National Unemp. Rate ) }\end{array}$} & -0.014 & -0.015 & -0.014 & -0.013 & -0.016 & -0.021 & -0.021 & -0.018 & 0.117 \\
\hline & $(0.119)$ & $(0.119)$ & $(0.118)$ & $(0.118)$ & $(0.118)$ & $(0.117)$ & $(0.116)$ & $(0.115)$ & $(0.023)$ \\
\hline & [0.908] & [0.903] & [0.908] & [0.909] & [0.892] & {$[0.855]$} & [0.859] & {$[0.875]$} & {$[0.000]$} \\
\hline \multirow[t]{3}{*}{$\log ($ Avg. UI WBA $) \times$ Age } & & 0.009 & & & & & & 0.010 & \\
\hline & & $(0.008)$ & & & & & & $(0.010)$ & \\
\hline & & {$[0.256]$} & & & & & & [0.333] & \\
\hline \multirow{3}{*}{$\log ($ Avg. UI WBA $) \times 1$ Married $\}$} & & & 0.003 & & & & & -0.080 & \\
\hline & & & $(0.177)$ & & & & & $(0.202)$ & \\
\hline & & & [0.988] & & & & & [0.693] & \\
\hline \multirow{3}{*}{$\begin{array}{l}\log (\text { Avg. UI WBA }) \times \\
\text { Years of Education }\end{array}$} & & & & 0.050 & & & & 0.050 & \\
\hline & & & & $(0.026)$ & & & & $(0.028)$ & \\
\hline & & & & {$[0.053]$} & & & & [0.079] & \\
\hline \multirow{3}{*}{$\begin{array}{l}\log (\text { Avg. UI WBA }) \times \\
\log (\text { pre-unemp. wage })\end{array}$} & & & & & 0.118 & & & 0.029 & \\
\hline & & & & & $(0.110)$ & & & $(0.152)$ & \\
\hline & & & & & {$[0.283]$} & & & [0.849] & \\
\hline Number of Spells & 4307 & 4307 & 4307 & 4307 & 4307 & 4307 & 4307 & 4307 & 16322 \\
\hline $\log ($ Avg. UI WBA $) \times$ Occupation FEs & $\mathrm{N}$ & $\mathrm{N}$ & $\mathrm{N}$ & $\mathrm{N}$ & $\mathrm{N}$ & $\mathrm{Y}$ & $\mathrm{N}$ & $\mathrm{Y}$ & $\mathrm{Y}$ \\
\hline $\log ($ Avg. UI WBA $) \times$ Industry FEs & $\mathrm{N}$ & $\mathrm{N}$ & $\mathrm{N}$ & $\mathrm{N}$ & $\mathrm{N}$ & $\mathrm{N}$ & $\mathrm{Y}$ & $\mathrm{Y}$ & $\mathrm{Y}$ \\
\hline \multirow[t]{3}{*}{ Post-estimation: $\mathbf{( A )}+\sigma \times \mathbf{( B )}$} & -0.304 & -0.295 & -0.305 & -0.284 & -0.299 & -0.228 & -0.233 & -0.196 & 0.036 \\
\hline & $(0.300)$ & $(0.298)$ & $(0.300)$ & $(0.296)$ & $(0.298)$ & $(0.298)$ & $(0.311)$ & $(0.296)$ & $(0.064)$ \\
\hline & {$[0.310]$} & [0.323] & [0.311] & [0.337] & {$[0.316]$} & {$[0.444]$} & [0.453] & [0.508] & [0.579] \\
\hline \multirow[t]{3}{*}{ Post-estimation: (A) $-\sigma \times \mathbf{( B )}$} & -0.822 & -0.807 & -0.822 & -0.798 & -0.820 & -0.749 & -0.730 & -0.705 & 0.174 \\
\hline & $(0.325)$ & $(0.319)$ & $(0.324)$ & $(0.320)$ & $(0.323)$ & $(0.328)$ & $(0.350)$ & (0.333) & $(0.100)$ \\
\hline & [0.011] & [0.012] & {$[0.011]$} & [0.013] & {$[0.011]$} & {$[0.022]$} & [0.037] & [0.034] & [0.083] \\
\hline
\end{tabular}

Notes: Columns (1) through (8) report semiparametric (Cox proportional) hazard model results from estimating equation (5) using individual-level unemployment spells from 1985-2000 SIPP. See Table 2 for more details on the baseline specification. Column (9) reports OLS estimates of take-up elasticity on a broader sample of all individuals deemed eligible for UI. The final two rows reports linear combinations of parameter estimates to produce the marginal effects when the state unemployment rate is one standard deviation above/below average. Standard errors, adjusted to allow for an arbitrary variance-covariance matrix for each state over time, are in parentheses and p-values are in brackets. 
Table 7

Alternative Measures of the Interaction Term

\begin{tabular}{|c|c|c|c|c|c|}
\hline \multirow[b]{2}{*}{$\begin{array}{l}\text { (1) (A) } \log (\text { Average UI WBA }) \times \\
\text { (B) } \log (\text { State Unemp. Rate / National Unemp. Rate })\end{array}$} & \multicolumn{3}{|c|}{ Hazard Model Results } & \multicolumn{2}{|c|}{$\begin{array}{c}\text { Post-estimation } \\
(\mathbf{A})+\sigma \times(\mathbf{B})(\mathbf{A})-\sigma \times(\mathbf{B})\end{array}$} \\
\hline & $\begin{array}{l}-0.563 \\
(0.300) \\
{[0.060]}\end{array}$ & $\begin{array}{r}1.262 \\
(0.434) \\
{[0.004]}\end{array}$ & $\begin{array}{l}-0.014 \\
(0.119) \\
{[0.908]}\end{array}$ & $\begin{array}{l}-0.304 \\
(0.300) \\
{[0.310]}\end{array}$ & $\begin{array}{r}-0.822 \\
(0.325) \\
{[0.011]}\end{array}$ \\
\hline $\begin{array}{l}\text { (2) (A) } \log (\text { Average UI WBA }) \times \\
\text { (B) } \mathbf{1}\{\text { State Unemp. Rate } \geq \text { Median }\}\end{array}$ & $\begin{array}{l}-1.205 \\
(0.359) \\
{[0.001]}\end{array}$ & $\begin{array}{r}0.968 \\
(0.199) \\
{[0.000]}\end{array}$ & $\begin{array}{l}-0.016 \\
(0.044) \\
{[0.716]}\end{array}$ & $\begin{array}{l}-0.236 \\
(0.313) \\
{[0.450]}\end{array}$ & N/A \\
\hline $\begin{array}{l}\text { (3) (A) } \log (\text { Average UI WBA }) \times \\
\text { (B) (State Unemp. Rate - National Unemp. Rate) }\end{array}$ & $\begin{array}{l}-0.520 \\
(0.327) \\
{[0.112]}\end{array}$ & $\begin{array}{r}0.137 \\
(0.069) \\
{[0.047]}\end{array}$ & $\begin{array}{l}-0.001 \\
(0.018) \\
{[0.969]}\end{array}$ & $\begin{array}{l}-0.337 \\
(0.314) \\
{[0.283]}\end{array}$ & $\begin{array}{l}-0.702 \\
(0.363) \\
{[0.053]}\end{array}$ \\
\hline $\begin{array}{l}\text { (4) (A) } \log \text { (Average UI Replacement Rate) } \times \\
\text { (B) } \log \text { (State Unemp. Rate / National Unemp. Rate) }\end{array}$ & $\begin{array}{l}-0.425 \\
(0.258) \\
{[0.099]}\end{array}$ & $\begin{array}{r}1.425 \\
(0.506) \\
{[0.005]}\end{array}$ & $\begin{array}{l}-0.010 \\
(0.111) \\
{[0.926]}\end{array}$ & $\begin{array}{l}-0.133 \\
(0.286) \\
{[0.641]}\end{array}$ & $\begin{array}{l}-0.717 \\
(0.269) \\
{[0.008]}\end{array}$ \\
\hline $\begin{array}{l}\text { (5) (A) } \log (\text { Simulated Average UI WBA }) \times \\
\text { (B) } \log (\text { State Unemp. Rate / National Unemp. Rate })\end{array}$ & $\begin{array}{l}-0.827 \\
(0.352) \\
{[0.019]}\end{array}$ & $\begin{array}{r}1.232 \\
(0.776) \\
{[0.112]}\end{array}$ & $\begin{array}{r}0.010 \\
(0.119) \\
{[0.930]}\end{array}$ & $\begin{array}{l}-0.574 \\
(0.344) \\
{[0.095]}\end{array}$ & $\begin{array}{l}-1.079 \\
(0.425) \\
{[0.011]}\end{array}$ \\
\hline $\begin{array}{l}\text { (6) (A) } \log (\text { Average UI WBA }) \times \\
\text { (B) }-1 * \log (\text { Predicted Employment-to-Pop Ratio) }\end{array}$ & $\begin{array}{l}-0.683 \\
(0.402) \\
{[0.089]}\end{array}$ & $\begin{array}{r}0.866 \\
(1.042) \\
{[0.406]}\end{array}$ & $\begin{array}{l}-0.134 \\
(0.378) \\
{[0.723]}\end{array}$ & $\begin{array}{l}-0.506 \\
(0.318) \\
{[0.112]}\end{array}$ & $\begin{array}{l}-0.860 \\
(0.559) \\
{[0.124]}\end{array}$ \\
\hline $\begin{array}{l}\text { (7) (A) } \log (\text { Average UI WBA }) \times \\
\text { (B) Average of } \log (\text { State Unemp. Rate / } \\
\text { Nat'l Unemp. Rate }), 1985-2000 \\
\text { (A') } \log (\text { Average UI WBA }) \times \\
\text { (B') }(\log (\text { State Unemp. Rate / National Unemp. Rate })-(\text { B) }) \\
\text { p-value of test (B) }=\end{array}$ & $\begin{array}{l}-0.616 \\
(0.364) \\
{[0.090]}\end{array}$ & $\begin{array}{r}2.833 \\
(2.123) \\
{[0.182]} \\
1.066 \\
(0.467) \\
{[0.022]} \\
\end{array}$ & $\begin{array}{r}-1.474 \\
(0.514) \\
{[0.004]} \\
-0.026 \\
(0.120) \\
{[0.823]}\end{array}$ & $\begin{array}{r}-0.176 \\
(0.362) \\
{[0.628]} \\
-0.466 \\
(0.378) \\
{[0.217]}\end{array}$ & $\begin{array}{r}-1.056 \\
(0.592) \\
{[0.075]} \\
-0.766 \\
(0.361) \\
{[0.034]}\end{array}$ \\
\hline
\end{tabular}

Notes: All rows report semiparametric (Cox proportional) hazard model results from estimating equation (5); each column reports separate parameter estimates. Data are individual-level unemployment spells from 1985-2000 SIPP. Number of spells $=4307$. See Table 2 for more details on the baseline specification. In rows (1), (2), (6), and (7), the median unemployment rate across all states in sample is calculated separately each year. In row (3), the Average UI WBA is the average weekly benefit amount paid to individuals claiming unemployment insurance. In row (4), the Average UI Replacement Rate is the Average UI WBA divided by the average weekly wages in a given state-year for prime-age males (computed using the CPS). In row (5), the Simulated Average UI WBA is constructed following the simulated instrumental variables procedure in Currie and Gruber (1996), isolating variation in generosity due to changes in program parameters, holding composition of unemployed constant. In row (6), the Predicted Employment to Population Ratio is computed following the "shift share" procedure of Bartik (1991); see text for details. In row (7), the interaction term is split into two separate interaction terms to decompose the variation in the relative unemployment rate between within-state and between-state variation. Across all rows, the final two columns report linear combinations of parameter estimates to produce the duration elasticity when the state unemployment rate is one standard deviation above/below the mean. In row (2), we set $\sigma=1.0$ becasue the interaction term includes a dummy variable rather than a continuous measure. Standard errors, adjusted to allow for an arbitrary variance-covariance matrix for each state over time, are in parentheses and p-values are in brackets. 
Table 8

How Does Effect of UI on Consumption Change Upon Unemployment Vary with the Unemployment Rate?

\begin{tabular}{|c|c|c|c|c|c|c|}
\hline & $\begin{array}{c}\text { Gruber } \\
\text { (1997), } \\
\text { Table 1, } \\
\text { column (4) }\end{array}$ & \multicolumn{5}{|c|}{ Replication Sample } \\
\hline & (1) & (2) & (3) & (4) & (5) & (6) \\
\hline UI replacement rate & $\begin{array}{r}0.280 \\
(0.105)\end{array}$ & $\begin{array}{r}0.255 \\
(0.116) \\
{[0.034]}\end{array}$ & $\begin{array}{r}0.257 \\
(0.115) \\
{[0.031]}\end{array}$ & $\begin{array}{r}0.245 \\
(0.112) \\
{[0.034]}\end{array}$ & $\begin{array}{r}0.224 \\
(0.128) \\
{[0.087]}\end{array}$ & $\begin{array}{r}0.244 \\
(0.116) \\
{[0.042]}\end{array}$ \\
\hline Implied consumption change at replacement rate of 0 & -0.231 & -0.253 & -0.254 & -0.247 & -0.237 & -0.243 \\
\hline $\begin{array}{l}\text { UI replacement rate } \times \\
\log (\text { State Unemp. Rate / National Unemp. Rate) }\end{array}$ & & & $\begin{array}{r}0.004 \\
(0.213) \\
{[0.985]}\end{array}$ & $\begin{array}{r}0.069 \\
(0.221) \\
{[0.756]}\end{array}$ & $\begin{array}{r}0.027 \\
(0.223) \\
{[0.903]}\end{array}$ & $\begin{array}{r}0.065 \\
(0.232) \\
{[0.781]}\end{array}$ \\
\hline log(State Unemp. Rate / National Unemp. Rate) & & & $\begin{array}{l}-0.033 \\
(0.155) \\
{[0.833]}\end{array}$ & $\begin{array}{l}-0.080 \\
(0.178) \\
{[0.654]}\end{array}$ & $\begin{array}{r}0.108 \\
(0.207) \\
{[0.605]}\end{array}$ & $\begin{array}{l}-0.095 \\
(0.189) \\
{[0.617]}\end{array}$ \\
\hline $\mathrm{N}$ & 1604 & 1595 & 1595 & 1595 & 1595 & 1595 \\
\hline $\mathrm{R}^{2}$ & & 0.099 & 0.099 & 0.104 & 0.164 & 0.114 \\
\hline State and Year FEs & $\mathrm{Y}$ & $\mathrm{Y}$ & $\mathrm{Y}$ & $\mathrm{Y}$ & $\mathrm{Y}$ & $\mathrm{Y}$ \\
\hline Region-specific linear trends & $\mathrm{N}$ & $\mathrm{N}$ & $\mathrm{N}$ & Y & $\mathrm{N}$ & $\mathrm{N}$ \\
\hline Region $\times$ Year FEs & $\mathrm{N}$ & $\mathrm{N}$ & $\mathrm{N}$ & $\mathrm{N}$ & $\mathrm{Y}$ & $\mathrm{N}$ \\
\hline State-specific linear trends & $\mathrm{N}$ & $\mathrm{N}$ & $\mathrm{N}$ & $\mathrm{N}$ & $\mathrm{N}$ & $\mathrm{Y}$ \\
\hline Post-estimation: (A) $+\sigma \times$ (B) & & & $\begin{array}{r}0.259 \\
(0.137)\end{array}$ & $\begin{array}{r}0.264 \\
(0.131)\end{array}$ & $\begin{array}{r}0.232 \\
(0.145)\end{array}$ & $\begin{array}{r}0.262 \\
(0.137)\end{array}$ \\
\hline Post-estimation: (A) $-\sigma \times$ (B) & $\begin{array}{r}0.280 \\
(0.105)\end{array}$ & $\begin{array}{r}0.255 \\
(0.116) \\
{[0.034]}\end{array}$ & $\begin{array}{r}{[0.060]} \\
0.256 \\
(0.120)\end{array}$ & $\begin{array}{r}{[0.044]} \\
0.226 \\
(0.122)\end{array}$ & $\begin{array}{r}{[0.110]} \\
0.216 \\
(0.138)\end{array}$ & $\begin{array}{r}{[0.056]} \\
0.226 \\
(0.127)\end{array}$ \\
\hline & & & [0.033] & {$[0.065]$} & {$[0.117]$} & {$[0.076]$} \\
\hline
\end{tabular}

Notes: Column (1) reproduces the results from column (4) in Gruber (1997), Table 1. Remainder of columns report OLS results from estimating equation (8) on a replication sample. Data are individual-level observations from 19681987 PSID. See text for more details on the baseline specification. The implied consumption drop is computed as the average fitted value across the sample when the replacement rate is set to 0 for all observations. Standard errors, adjusted to allow for an arbitrary variance-covariance matrix for each state over time, are in parentheses and p-values are in brackets. 
Table 9

Moral Hazard and Net Liquid Wealth

\begin{tabular}{|c|c|c|c|c|c|}
\hline & (1) & (2) & (3) & (4) & (5) \\
\hline \multirow[t]{3}{*}{ log(Average UI WBA) } & -0.563 & -0.674 & -0.563 & & \\
\hline & $(0.300)$ & $(0.452)$ & $(0.289)$ & & \\
\hline & {$[0.060]$} & {$[0.136]$} & {$[0.052]$} & & \\
\hline \multirow{3}{*}{$\begin{array}{l}\log (\text { Average UI WBA }) \times \\
\quad \log (\text { State Unemp. Rate / National Unemp. Rate })\end{array}$} & 1.262 & 1.520 & 1.427 & 1.494 & 1.720 \\
\hline & $(0.434)$ & $(0.729)$ & $(0.466)$ & $(0.481)$ & $(0.593)$ \\
\hline & {$[0.004]$} & {$[0.037]$} & {$[0.002]$} & [0.002] & [0.004] \\
\hline \multirow{3}{*}{$\begin{array}{l}\log (\text { Average UI WBA }) \times \\
\log (\text { State Unemp. Rate / National Unemp. Rate }) \times \\
\mathbf{1}\{1 \text { st and 2nd liquid wealth quartiles }\}\end{array}$} & & & & & -0.557 \\
\hline & & & & & $(0.691)$ \\
\hline & & & & & {$[0.420]$} \\
\hline Number of Spells & 4307 & 2170 & 4307 & 4307 & 4307 \\
\hline 3rd and 4th liquid wealth quartiles only & $\mathrm{N}$ & $\mathrm{Y}$ & $\mathrm{N}$ & $\mathrm{N}$ & $\mathrm{N}$ \\
\hline Occupation FEs $\times$ Liquid wealth quartile & $\mathrm{N}$ & $\mathrm{N}$ & $\mathrm{Y}$ & $\mathrm{Y}$ & $\mathrm{Y}$ \\
\hline Industry FEs $\times$ Liquid wealth quartile & $\mathrm{N}$ & $\mathrm{N}$ & $\mathrm{Y}$ & $\mathrm{Y}$ & $\mathrm{Y}$ \\
\hline $\log ($ Average UI WBA $) \times$ Liquid wealth quartile & $\mathrm{N}$ & $\mathrm{N}$ & $\mathrm{N}$ & $\mathrm{Y}$ & $\mathrm{Y}$ \\
\hline \multirow[t]{3}{*}{ Post-estimation: (A) $+\sigma \times(\mathbf{B})$} & -0.304 & -0.363 & -0.270 & & \\
\hline & $(0.300)$ & $(0.455)$ & $(0.295)$ & & \\
\hline & {$[0.310]$} & {$[0.426]$} & [0.359] & & \\
\hline \multirow[t]{3}{*}{ Post-estimation: (A) $-\sigma \times$ (B) } & -0.822 & -0.986 & -0.855 & & \\
\hline & $(0.325)$ & $(0.495)$ & $(0.315)$ & & \\
\hline & [0.011] & {$[0.047]$} & {$[0.007]$} & & \\
\hline
\end{tabular}

Notes: All columns report semiparametric (Cox proportional) hazard model results from estimating equation (5). Data are individual-level unemployment spells from 1985-2000 SIPP. See Table 2 for more details on the baseline specification. The final two rows reports linear combinations of parameter estimates to produce the duration elasticity when the state unemployment rate is one standard deviation above/below average.

Standard errors, adjusted to allow for an arbitrary variance-covariance matrix for each state over time, are in parentheses and p-values are in brackets. 
Table 10

Sufficient Statistics Calibrations:

Optimal UI and the Unemployment Rate

\begin{tabular}{cccccc}
\hline \hline$u$ & $3.6 \%$ & $4.9 \%$ & $6.2 \%$ & $7.5 \%$ & $8.8 \%$ \\
$\varepsilon_{D, b}$ & 1.249 & 0.860 & 0.563 & 0.323 & 0.121 \\
\hline \multicolumn{5}{c}{ Panel A: Coefficient of Relative Risk Aversion, $\gamma=2$} \\
$r^{*}$ & $0.8 \%$ & $2.3 \%$ & $17.7 \%$ & $44.8 \%$ & $73.1 \%$ \\
$b^{*}$ & $\$ 3$ & $\$ 8$ & $\$ 62$ & $\$ 157$ & $\$ 256$ \\
\multicolumn{7}{c}{ Panel B: Coefficient of Relative Risk Aversion, $\gamma=3$} \\
$r^{*}$ & $6.4 \%$ & $23.8 \%$ & $42.8 \%$ & $61.4 \%$ & $80.3 \%$ \\
$b^{*}$ & $\$ 22$ & $\$ 83$ & $\$ 150$ & $\$ 215$ & $\$ 281$ \\
\multicolumn{7}{c}{ Panel C: Coefficient of Relative Risk Aversion, $\gamma=4$} \\
$r^{*}$ & $26.5 \%$ & $42.0 \%$ & $56.2 \%$ & $70.0 \%$ & $83.9 \%$ \\
$b^{*}$ & $\$ 93$ & $\$ 147$ & $\$ 197$ & $\$ 245$ & $\$ 293$ \\
\hline \hline
\end{tabular}

Notes: All columns report optimal UI benefit levels at various levels of the unemployment rate. Subsequent rows report the elasticity of unemployment duration with respect to UI benefit level, the optimal UI benefit level $\left(b^{*}\right)$ and the optimal UI replacement rate $\left(r^{*}\right)$. The optimal replacement rate is computed by dividing UI benefit level by the average wage. See Section 4 for more details on the computations. The optimal benefit level is computed assuming a weekly wage of $\$ 350$. 
Figure 1: Model Simulation

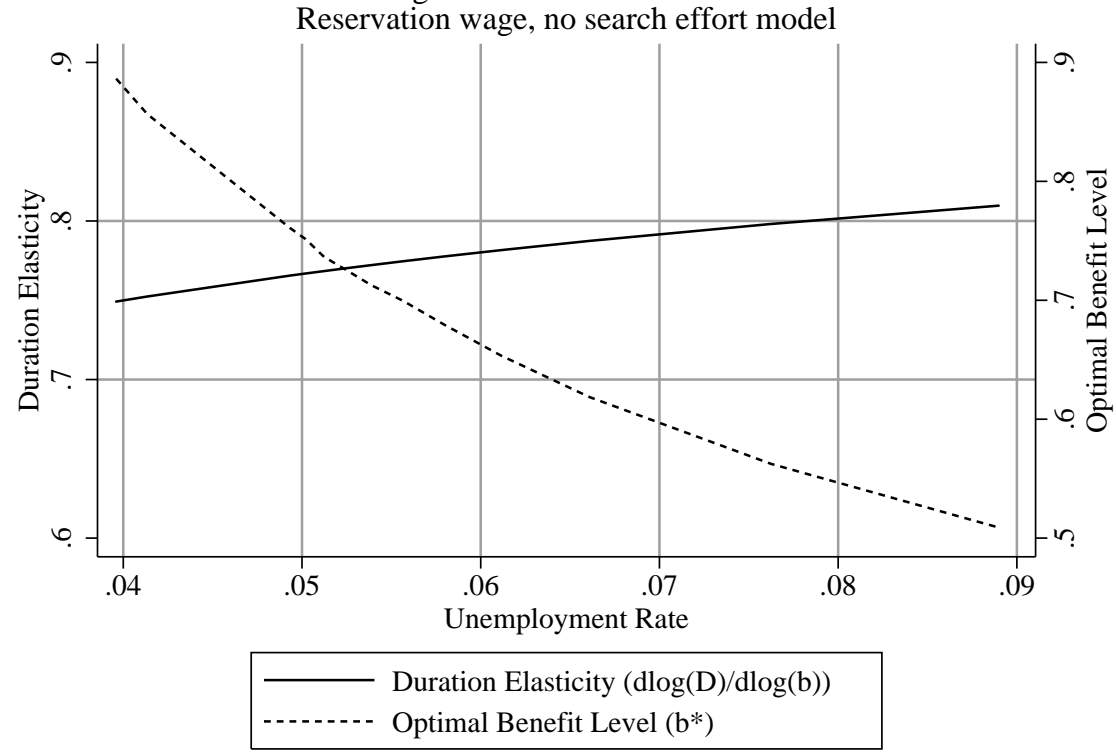

Notes: This figure is generated by calibrating the job search model in the main text with the following parameters. The benefit level is set to $b=0.0667$. The wage distribution is assumed to be log-normal with mean 0.1 and standard deviation of 0.05 . There is no discounting and interest rate is set to 0 (i.e., $r=\rho=0$ ). The job offer arrival rate is $\lambda(e, \alpha)=\alpha$; i.e., there is no search effort decision. The job separation rate is $s=0.0012$. The coefficient of relative risk aversion is $\gamma=1.5$.

Figure 2: Model Simulation

Fixed wage, endogenous search effort model

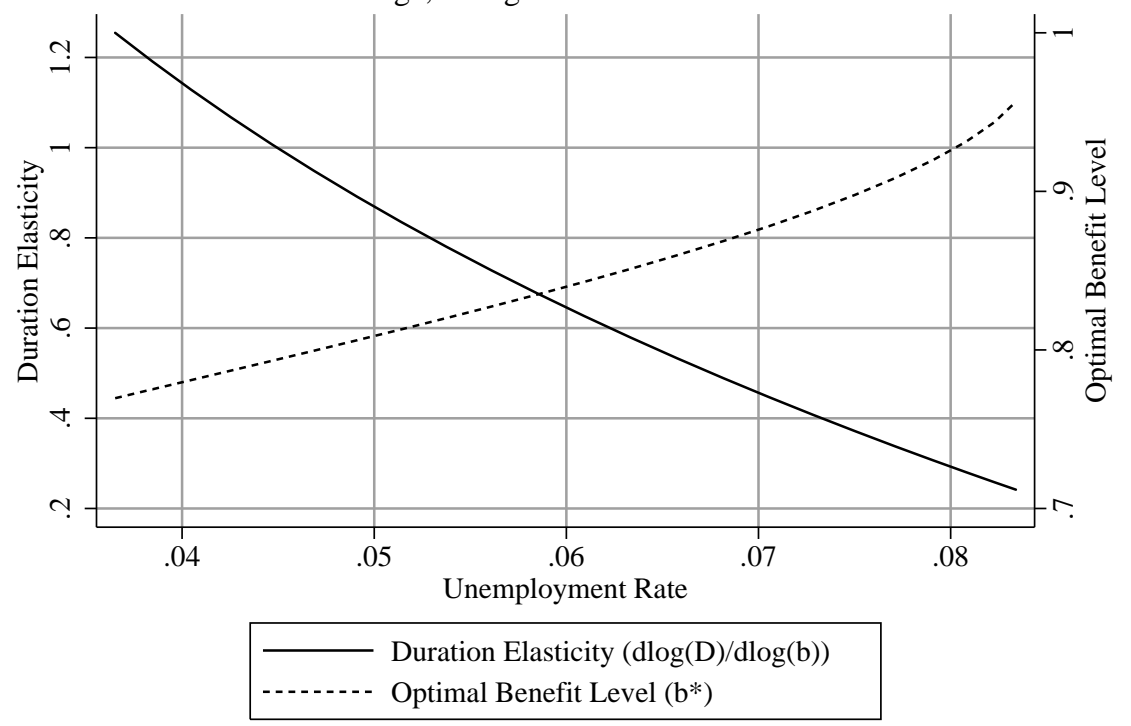

Notes: This figure is generated by calibrating the job search model in the main text with the following parameters. The benefit level is set to $b=0.125$. The wage distribution is degenerate with mean 0.25 . The benefit level is set to 0.125 . There is no discounting and interest rate is set to 0 (i.e., $r=\rho=0$ ). The job offer arrival rate is $\lambda(e, \alpha)=\Lambda e^{\alpha}$, with $\Lambda=0.1$. The cost of search is $\phi e^{\kappa}$, with $\phi=0.3$ and $\kappa=2.1$. The job separation rate is $s=0.0089$. The coefficient of relative risk aversion is $\gamma=3.0$. 
Figure 3

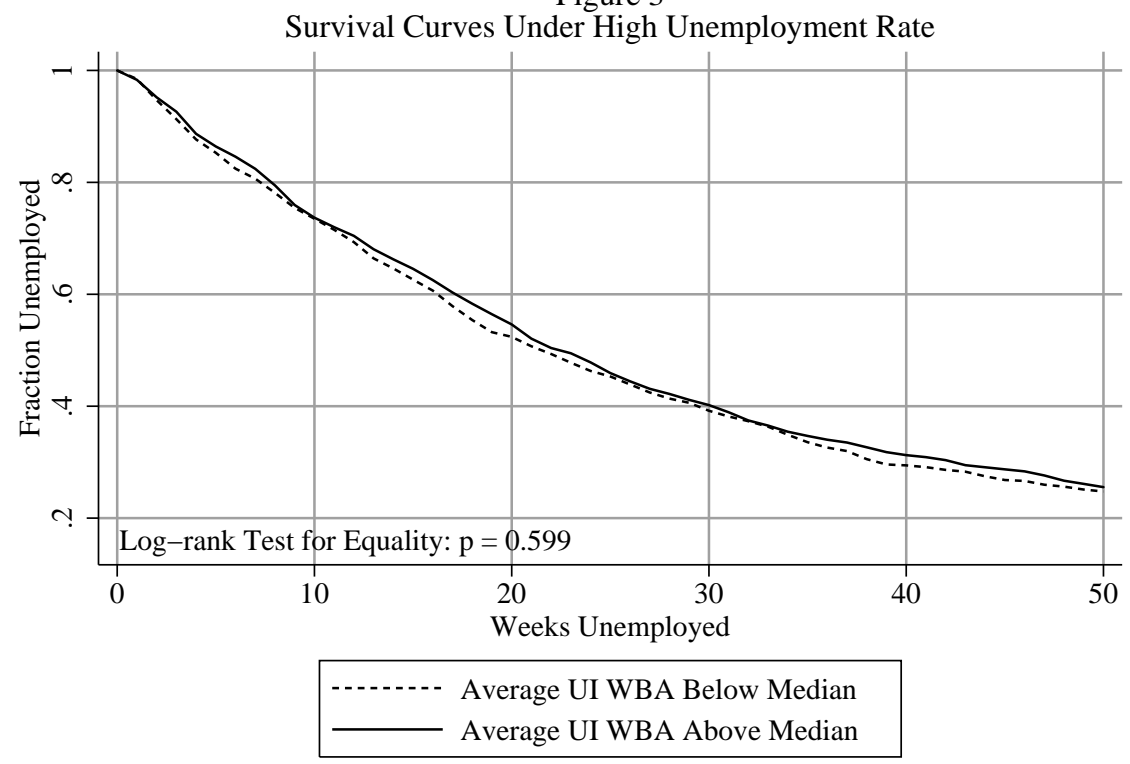

Figure 4

Survival Curves Under Low Unemployment Rate

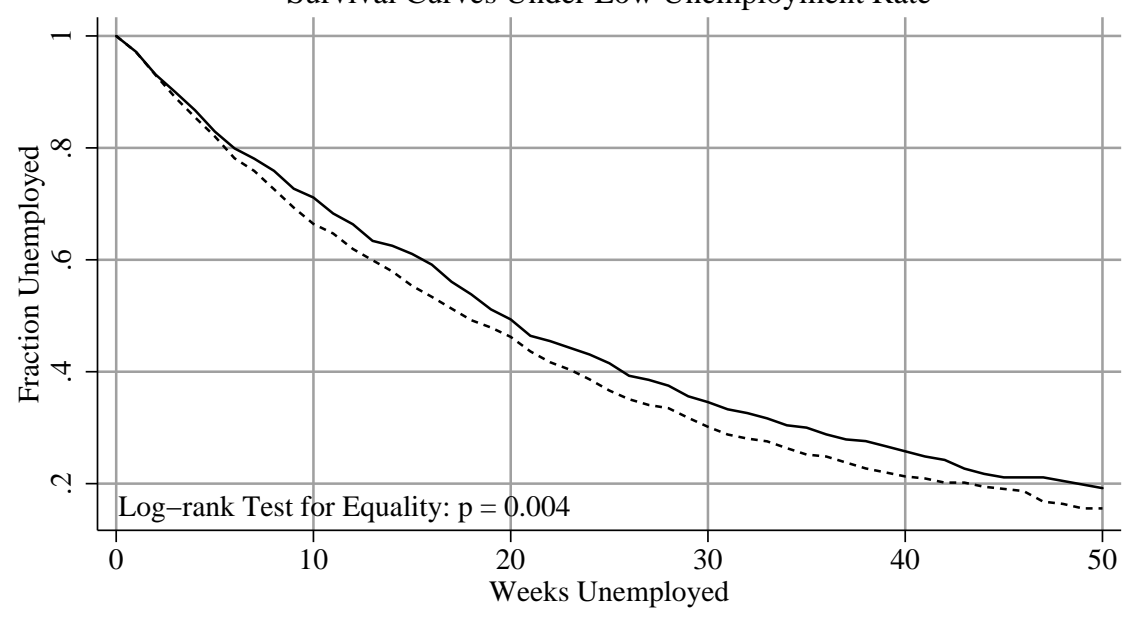

-..- Average UI WBA Below Median

Average UI WBA Above Median

Notes: Data are individual-level unemployment spells from 1985-2000 SIPP. Each figure plots (Kaplan-Meier) survival curves for two groups of individuals based on whether or not Average UI Weekly Benefit Amount (WBA) in individual's state is above or below the median. The survival curves are adjusted following Chetty (2008), which parametrically adjusts for "seam effect" by fitting a Cox proportional hazard model with a seam dummy and then recovering the baseline hazard. 